\begin{abstract}
This paper analyses patterns of production across 14 industries in 45 regions from 7 European countries since 1975. We estimate a structural equation derived directly from HeckscherOhlin theory that relates an industry's share of a region's GDP to factor endowments and relative prices. Factor endowments are found to play a statistically significant and quantitatively important role in explaining production patterns. The explanation is most successful for aggregate industries, such as Agriculture, Manufacturing, and Services, and works less well for disaggregated industries within Manufacturing. We find no evidence that increasing European integration has weakened the relationship between factor endowments and production patterns within countries.
\end{abstract}

Keywords: Factor Endowments, Heckscher-Ohlin, specialization, European integration JEL Classification: F11, F14, R13

This paper was produced as part of the Centre's

Globalisation Programme 


\section{Factor Endowments and Production in European Regions}

Stephen Redding and Mercedes Vera-Martin 
Published by

Centre for Economic Performance

London School of Economics and Political Science

Houghton Street

London WC2A 2AE

(C) Stephen Redding and Mercedes Vera-Martin, submitted April 2001

ISBN 0753014734

Individual copy price: $£ 5$ 


\section{Factor Endowments and Production in European Regions}

\section{Stephen Redding and Mercedes Vera-Martin}

1. Introduction 2

2. Heckscher-Ohlin Theory 6

3. Data Description and Analysis 9

4. Economietric Specification 11

5. Empirical Results 16

6. Conclusions 21

Tables 23

Figure 36

$\begin{array}{ll}\text { Appendix A } & 37\end{array}$

$\begin{array}{ll}\text { Appendix B } & 39\end{array}$

B.1 Regional-level data on production and endowments 39

B.2 Summary of educational attainment data sources 39

$\begin{array}{ll}\text { Appendix C } & 41\end{array}$

$\begin{array}{ll}\text { References } & 42\end{array}$

The Centre for Economic Performance is financed by the Economic and Social Research Council. 


\section{Acknowledgements}

Mercedes Vera-Martin's research was funded by a Central Bank of Spain Scholarship. We are very grateful to Oriana Bandiera, James Harrigan, Steve Nickell, Francois Ortalo-Magne, Henry Overman, Jo Swaffield, Tony Venables, AlanWinters, and seminar participants at the London School of Economics for helpful comments and suggestions. We would like to thank Maia Guell-Rotllan, Steve Machin, Marco Manacorda, Steve Nickell, Jan van Ours, Henry Overman, and Jo Swaffield for their help with the data. We are also grateful to Giorgia Albertin and Estela Montado for research assistance. Responsibility for any results, opinions, and errors lies with the authors alone.

Stephen Redding is a member of the Centre for Economic Performance and Department of Economics, London School of Economics, Houghton Street, London WC2A 2AE, United Kingdom. Tel: + 44207955 7483. Fax: + 44207831 1840. E-mail: s.j.redding@1se.ac.uk. Web: http://econ.lse.ac.uk/ sredding/. Mercedes Vera-Martin is a member of the Centre for Economic Performance, London School of Economics, Houghton Street, London WC2A 2AE. E-mail: m.vera-martin@1se.ac.uk 


\section{Introduction}

"One of the best ways to understand how the international economy works is to start looking at what happens inside nations ... The data will be better and pose fewer problems of compatibility, and the underlying economic forces will be less distorted by government policies." 1

One of the most influential conceptual frameworks for theoretical and empirical work in international trade is the Heckscher-Ohlin (HO) model. A key attraction is the model's ability to yield precisely formulated theoretical predictions, which are amenable to direct empirical testing. However, a number of cross-country studies have called into question its empirical validity. For example, using data on cross-country trade in factor services, Bowen et al. (1987) reject the HO model against more general alternatives including measurement error and neutral technology differences. ${ }^{2}$ This paper examines the ability of the HO model to explain patterns of production at the regional level in Europe using a newly constructed panel dataset on output and factor endowments in 45 NUTS-1 regions from 7 European countries since $1975 .{ }^{3}$ A number of reasons have been put forward for the disappointing empirical results at the country-level. The use of regional data enables us to abstract from many of these reasons - for example, both measurement error and technology differences are likely to be much smaller across regions within Europe than in a cross-section of developed and developing countries. The European Union provides an interesting laboratory within which to explore the relationship between factor endowments and patterns of production. The ongoing process of European economic integration introduces exogenous variation in relative prices. We are careful to control for this variation, and examine whether the relationship between factor endowments and patterns of production within countries has been strengthened or weakened by closer economic integration.

Much existing empirical work on the international location of production has, for reasons of data availability, been concerned with the manufacturing sector. This paper explicitly considers both manufacturing and non-manufacturing, where the latter accounts for more than $70 \%$ of GDP in many NUTS-1 regions. We focus on patterns of production rather than trade, because the central predictions of the $\mathrm{HO}$ model are for producer equilibrium and, in so doing, we abstract from any violations of the model's assumptions concerning consumer behaviour. ${ }^{4}$ Data are available on five

\footnotetext{
${ }^{1}$ Paul Krugman, Geography and Trade, MIT Press, 1991, page 3, cited in Bernstein and Weinstein (1998).

${ }^{2}$ See also Trefler (1995), Davis et al. (1997), Gabaix (1997), and Davis and Weinstein (1998). The HOV model's empirical validity has remained in question since the debate concerning the 'Leontief Paradox' (see, for example, Leontief (1953) and Leamer (1980)).

${ }^{3}$ NUTS stands for Nomenclature of Statistical Territorial Units. NUTS-1 regions are the first-tier of sub-national geographical units for which Eurostat collects data on the EU member countries. See Appendix A for more details concerning the data used.

${ }^{4}$ Three of the HO model's four key theorems - the Rybczynski, Stolper-Samuelson, and Factor Price Equalisation
} 
factor endowments: high-education, medium-education, and low education individuals, physical capital, and land area. With the exception of land area, four of these endowments exhibit a degree of mobility across regions within a country. This is entirely consistent with our approach. The analysis shows that, under the assumptions of the Heckscher-Ohlin model and with factor price equalization within countries, the same relationship between production and factor endowments exists whether factor endowments are perfectly mobile across regions within a country or perfectly immobile.

We find substantial variation in patterns of production and factor endowments, both across European regions at a point in time and in individual regions over time. Across a wide range of different econometric specifications, there is a statistically significant relationship between factor endowments and patterns of production. Increases in physical capital are associated with a higher share of Manufacturing in a region's GDP and a lower share of Agriculture and Services. Movements from low to medium educational attainment are negatively related to specialization in Agriculture and positively related to specialization in Manufacturing. In contrast, movements from medium to high educational attainment are associated with a reduction in the share of Manufacturing in GDP and an increase in the share of Services. These effects are quantitatively important: including information on factor endowments reduces the model's average within-sample proportional prediction error by around $350 \%$. Among the three aggregate industries considered, factor endowments are most successful at explaining regional specialization in Services and Manufacturing. Across regions within each country, we typically find the same ranking of industries in terms of (increasing) average prediction errors, from Services, through Manufacturing, to Agriculture. There is no evidence that the process of increasing economic integration in Europe has weakened the relationship between patterns of production and factor endowments within countries. We find evidence in favour of a hypothesis that has been frequently assumed in theoretical and empirical work, but has rarely been systematically examined empirically. That is, factor endowments are more successful in explaining patterns of production at the aggregate level (Agriculture, Manufacturing, and Services) than in disaggregated industries within the manufacturing sector.

A number of papers have considered the relationship between factor endowments and international trade in factor services at the country-level, including Leamer (1984), Bowen et al. (1987), Trefler (1995), Davis et al. (1997), Gabaix (1997), and Davis and Weinstein (1998). As discussed above, this literature typically finds that the HO model is rejected against more general alternatives. Davis and Weinstein (1998) argue that, with a few plausible amendments, including cross-country differences in technology and a more flexible specification of preferences, the HO model is consistent 
with international data on trade in factor services. Although, the model is no longer Heckscher-Ohlin as traditionally conceived or strictly interpreted. The first paper to examine the empirical predictions of the HO model for the location of production was Harrigan (1995), which used data on 10 manufacturing industries in 20 OECD countries during 1970-85. Factor endowments were found to account for much of the variation in output, although average prediction errors, expressed as a percentage of actual production were around $40 \%$. Physical capital was found to be an important determinant of manufacturing output, although the effects of endowments of skilled and unskilled labour were more ambiguous. Harrigan (1997) and Harrigan and Zakrajsek (1999) use country-level data to estimate the neoclassical model of trade, which generalizes the HO model to allow cross-country differences in technology and preferences. Harrigan (1997) finds that both relative technology levels and factor endowments are important determinants of patterns of production. Redding (1999) uses the neoclassical model to analyze the dynamics of countries' production patterns, while Nickell et al. (2000) use a newly constructed and disaggregated dataset on educational attainment in OECD countries to analyze the relationship between changing levels of educational attainment and production patterns.

An emerging empirical literature has recently begun to examine the predictions of the HO model using regional-data. Davis et al. (1997) analyze trade in factor services using both country-level and Japanese regional data. The data on production in Japanese regions are found to be consistent with factor price equalization. When the model is applied to data on regional rather than countrylevel data on trade in factor services, the empirical results are much more favourable. Bernstein and Weinstein (1998) use more disaggregated Japanese regional data to examine the relationship between factor endowments and the location of production. The data are again consistent with factor price equalization. However, there are substantial within-sample prediction errors, which Bernstein and Weinstein interpret as evidence of production indeterminacy. Hanson and Slaughter (1999) use data on immigration in US States to test a generalization of the Rybczynski Theorem, which predicts that regions will accommodate immigrant inflows by changes in output mix rather than changes in relative factor prices. ${ }^{5}$ Changes in state output mix are found to broadly match changes in state endowments. Moreover, the variation in factor intensities across US States is found to be consistent with relative factor price equalization. Assuming that each US State is small, the latter is a sufficient condition for changes in endowments to be accommodated by changes in output mix.

A body of empirical work has sought to characterize the nature and evolution over time of specialization in Europe using country-level data: see, for example, Amiti (1999), Brulhart (2000), and Proudman and Redding (1998), (2000). Amiti (1999) finds evidence of increasing specialization

\footnotetext{
${ }^{5}$ See Gandal, Hanson, and Slaughter (1999) for a related analysis of immigration in Israel.
} 
in Europe using production and employment data, while Brulhart (2000) finds that specialization has increased in employment terms but remained roughly unchanged in export terms. Using export data and statistical techniques for modelling the evolution of entire distributions, Proudman and Redding (1998), (2000) find evidence of substantial changes in patterns of specialization over time. In contrast to all of these papers, which employ country-level data, Vera-Martin (2000) characterizes specialization at the regional-level in Europe for the same sample considered here.

Finally, the paper relates to a recent empirical literature on economic geography. Davis and Weinstein (1996), (1999) respectively use country and regional-level data to test for a 'home market' or 'magnification' effect. That is, in models of economic geography, the presence of increasing returns to scale and transport costs means that an increase in expenditure on a good has a more than proportionate effect on domestic production of the good. The same is not true in the constant returns to scale world of $\mathrm{HO}$, and this provides the basis for an identifying restriction. Using countrylevel data on OECD manufacturing industries, Davis and Weinstein (1996) find little evidence that considerations of economic geography are an important determinant of the structure of production. The analysis of regional-level data on Japanese manufacturing industries in Davis and Weinstein (1999) reveals evidence of economic geography effects in 8 out of 19 industries, and these effects are shown to be quantitatively important. Brulhart and Torstensson (1996) consider the effects of increasing integration on the location of increasing returns to scale industries and the pattern of international trade. Data on 11 European countries provide some empirical support for the predictions of an economic geography model: employment in increasing returns to scale industries tends to be concentrated at the centre of the EU and intra-industry trade is relatively low in these industries. Midelfart-Knarvik, Overman, and Venables (2000) employ European country-level data to analyze the determinants of specialization in manufacturing industries during 1970-97. A role is found for both the considerations of traditional trade theory (eg factor endowments and factor intensities) and those emphasized by the economic geography literature (eg geographical proximity and forward/backward linkages).

This paper uses European regional data to analyze the relationship between factor endowments and the pattern of production. The spirit of the analysis is to abstract from considerations extraneous to $\mathrm{HO}$ theory and to analyze how far we may proceed in the explanation of patterns of production simply within the context of this model - without having to invoke technology differences or introduce considerations of economic geography. We estimate a structural equation derived directly from the translog revenue function representation of the HO model. This relates the share of a sector in a region's GDP to factor endowments and relative prices. The presence of the term in relative prices 
enables us to explicitly control for the effects of ongoing economic integration in Europe. This is one advantage of the translog revenue function approach, which focuses on the relationship between shares of sectors in GDP and factor endowments, rather than directly analyzing the relationship between levels of production and factor endowments. While the main body of the paper focuses on the predictions of the HO model, we consider two alternative economic hypotheses. First, if regionindustry technology differences are introduced (as in the neoclassical model), a similar equation for the share of a sector in a region's GDP may be derived, but this relationship includes additional terms for relative technology levels. Second, if the HO model provides a correct characterization of the Data Generating Process (DGP), the revenue function should be linearly homogenous of degree 1 and there should be no spatial structure to the regression residuals. In contrast, models of economic geography, imply the existence of increasing returns to scale and suggest an omitted variable in the regression residuals which will be spatially correlated.

The paper is structured as follows. Section 2 provides a brief review of the revenue function representation of the Heckscher-Ohlin model. Section 3 undertakes a preliminary analysis of the data, while Section 4 discusses the econometric specification. Section 5 presents the main econometric results and evaluates the performance of the HO model. Section 6 summarizes our conclusions.

\section{Heckscher-Ohlin Theory}

We consider the Heckscher-Ohlin (HO) model as a special case of neoclassical trade theory as expounded by Dixit and Norman (1980) and Woodland (1982). Regions are indexed by $z \in\{1, \ldots, Z\}$, goods by $j \in\{1, \ldots, N\}$ and factors of production by $i \in\{1, \ldots, M\}$. Time is indexed by $t$. Regions are endowed with an exogenous vector of factors of production, $v_{z t}$. Production technologies and preferences are assumed to be identical across all regions. Production of each good occurs under conditions of perfect competition and constant returns to scale. General equilibrium in production may be characterized with the revenue function $r\left(p_{z t}, v_{z t}\right)$. As long as the latter is twice continuously differentiable, a region's equilibrium vector of net output supplies equals the gradient of the revenue function with respect to the price vector, $r_{p}\left(p_{z t}, v_{z t}\right)$.

We follow Harrigan (1997), Harrigan and Zakrajsek (1999), and Kohli (1991) in assuming a translog revenue function,

$$
\begin{array}{r}
\ln r\left(p_{z t}, v_{z t}\right)=\beta_{00}+\sum_{j} \beta_{0 j} \ln p_{z j t}+\frac{1}{2} \sum_{j} \sum_{k} \beta_{j k} \ln \left(p_{z j t}\right) \ln \left(p_{z k t}\right) \\
+\sum_{i} \delta_{0 i} \ln v_{z i t}+\frac{1}{2} \sum_{i} \sum_{h} \delta_{i h} \ln v_{z i t} \ln v_{z h t} \\
+\sum_{j} \sum_{i} \gamma_{j i} \ln \left(p_{z j t}\right) \ln v_{z i t}
\end{array}
$$


where $j, k \in\{1, . ., N\}$ index goods and $i, h \in\{1, . ., M\}$ index factors. Symmetry of the cross effects implies,

$$
\beta_{j k}=\beta_{k j} \quad \text { and } \quad \delta_{i h}=\delta_{h i} \quad \forall j, k, i, h
$$

Linear homogeneity of degree 1 in $v$ and $p$ requires,

$$
\sum_{j} \beta_{0 j}=1, \quad \sum_{i} \delta_{0 i}=1, \quad \sum_{j} \beta_{j k}=0, \quad \sum_{i} \delta_{i h}=0, \quad \sum_{i} \gamma_{j i}=0
$$

Differentiating the revenue function with respect to the price of good $j$, we obtain,

$$
s_{z j t} \equiv \frac{p_{z j t} y_{z j t}\left(p_{z t}, v_{z t}\right)}{r\left(p_{z t}, v_{z t}\right)}=\beta_{0 j}+\sum_{k} \beta_{j k} \ln p_{z k t}+\sum_{i} \gamma_{j i} \ln v_{z i t}
$$

A sector's share of a region's GDP, $s_{z j t}$, provides a natural and theory-consistent measure of specialization in a particular industry. Equation (4) constitutes a general equilibrium relationship between the share of a sector in GDP, relative prices, and factor endowments that must hold under the assumptions of the $\mathrm{HO}$ model. It is the starting point for the main econometric equation that we use below to analyze the empirical relationship between factor endowments and patterns of production at the regional level.

Before proceeding to the econometric estimation, it is worth noting two points. First, a key assumption in the derivation of equation (4) is that of identical technologies. Neoclassical trade theory provides a more general framework for explaining patterns of specialization than the HO model, in so far as it allows for differences in preferences and technologies. If there are Hicks-neutral technology differences across regions in particular industry-time period, the production function in each sector takes the form $y_{z j t}=\theta_{z j t} . F_{j}\left(v_{z j t}\right)$. In this case, the revenue function may be written as $r_{z}\left(p_{z t}, v_{z t}\right)=r\left(\theta_{z t} \cdot p_{z t}, v_{z t}\right)$, where $\theta_{z t}$ is an $n \times n$ diagonal matrix of the technology parameters $\theta_{z j t}{ }^{6}$ Changes in technology in industry $j$ of region $z$ are modelled in exactly the same way as changes in the price of industry $j$ output. The economy's vector of net outputs continues to be given by the gradient of the revenue function with respect to $p_{z t}$. Differentiating the revenue function with respect to the price of good $j$, we now obtain, ${ }^{7}$

$$
s_{z j t}=\beta_{0 j}+\sum_{k} \beta_{j k} \ln p_{z k t}+\sum_{k} \beta_{j k} \ln \theta_{z k t}+\sum_{i} \gamma_{j i} \ln v_{z i t}
$$

In addition to relative prices and factor endowments, region-industry-time technology levels play an important role in determining patterns of production. Equation (5) provides one explicit alternative hypothesis to the $\mathrm{HO}$ model.

\footnotetext{
${ }^{6}$ See Dixit and Norman (1980), pages 137-9.

${ }^{7}$ See Harrigan (1997).
} 
Second, another assumption in the derivation of equation (4) was that each region is endowed with an exogenous vector of factor endowments, $v_{z t}$. It could be argued that, while the assumption of exogenous factor endowments is plausible at the country-level, it is more problematic at the regionallevel due to factor mobility within countries. This is not clear. One of our factor endowments is regional land area, which, for fixed regional boundaries, is exogenous. Another of our factor endowments is labour (either total population or total population disaggregated by educational attainment). There is substantial empirical evidence that labour mobility (even of skilled labour) is surprisingly low across European regions. This is particularly true across countries, where language and other barriers operate, but is also true across regions within a country. ${ }^{8}$ Nonetheless, we consider the implications of relaxing the assumption that each region is endowed with an exogenous vector of factor endowments.

Even if we allow complete mobility of factors of production across European regions, it can be shown that the above general equilibrium relationship between patterns of specialization and factor endowments will continue to hold. For example, suppose that we make the conventional assumption that all factor endowments are perfectly immobile across countries, but assume that all factor endowments except land are perfectly mobile across regions within a country. In this case, patterns of specialization in regions within a country can be related to factor endowments using the concept of integrated equilibrium. This concept is conventionally applied at the world-level (looking across several countries), but here we apply it at the country-level (looking across several regions within a country). For example, consider a world of two countries (home and foreign), two regions (North and South), two goods, and two factor endowments. One factor endowment (land) is perfectly immobile across regions, while the second (labour) is perfectly mobile across regions within a country. We can solve for general equilibrium at the country-level using conventional techniques, and the relationship between factor endowments and patterns of specialization in equation (4) must hold.

Equilibrium at the regional level is analyzed diagrammatically in Figure 1. The box $O Z O^{*} Z^{*}$ denotes the home country's endowments of land and labour. Origin $O$ is for South and Origin $O^{*}$ is for North. The vectors $O A$ and $A O^{*}\left(O^{*} A^{*}\right.$ and $\left.A^{*} O\right)$ denote the home country's aggregate equilibrium allocation of factors of production to the two sectors. Mobility of labour implies that the (endogenous) allocation of factor endowments to the two regions must lie somewhere in the factor price equalization set $O A O^{*} A^{*}$ (eg at point $\left.E\right) .{ }^{9}$ At any such point within the factor price

\footnotetext{
${ }^{8} \mathrm{~A}$ number of authors find low levels of labour mobility within the United Kingdom. See, for example, McCormick (1997) and the discussion in Cameron and Muellbauer (1998).

${ }^{9}$ With one immobile factor and all regions sharing the same production technology, mobility of the remaining factor endowments implies that the free trade equilibrium must be characterised by factor price equalisation within countries.
} 
equalization set, we can find regional allocations of the two factors of production to each sector that exactly exhaust the region's endowment using the same equilibrium techniques of production as at the country-level. For endowment point $E$, these allocations correspond to the vectors $O B$ and $B E$ in South and $E B^{*}$ and $B^{*} O^{*}$ in North. The same general equilibrium relationship between factor endowments and production levels holds at the regional-level as at the country-level. Equation (4) holds for individual regions within the country.

The same analysis does not go through if there are region-industry-time technology differences. Mobile factors of production will continue to have an incentive to move (to high-technology regions) until real returns are equalized. However, the presence of technology differences means that the real return to the immobile factor will not, in general, be equalized. With varying relative factor prices, individual regions will, in general, use different equilibrium production techniques. The relationship between factor endowments and production levels will different in each region. Thus, as in the case of technology differences and immobile factors of production, equation (4) no longer holds.

\section{Data Description and Analysis}

The main source of data is the Regio dataset compiled by the European Statistics Office (Eurostat). We analyze patterns of production across 14 industries in 45 NUTS- 1 regions from 7 European countries since 1975. The choice of countries reflects the availability of data; we consider Belgium, France, Italy, Luxembourg, Netherlands, Spain, and the United Kingdom. ${ }^{10}$ As will be shown below, this is a group of countries among which there is substantial heterogeneity in patterns of production and factor endowments. The group includes several countries close to the 'core' of Europe (eg Belgium and France) and others located further towards the 'periphery' (eg Italy and Spain).

The number and size of NUTS-1 regions varies across European countries. This is perfectly consistent with our model, and the variation in size will be exploited in tests of the linear homogeneity restrictions implied by theory. In some European countries, such as Italy, the NUTS-1 regions correspond to the main regional political units. In the UK, they comprise geographical areas such as the North, South East, and South West. A full list of NUTS-1 regions in each country is given in Appendix A. We show below that there is also substantial variation in specialization and factor endowments across NUTS-1 regions within a country - from, for example, the North of Italy to Sicily.

Patterns of production are analyzed at two alternative levels of aggregation. First, we consider three aggregate (one-digit) industries: Agriculture, Manufacturing, and Services. Second, we exploit

\footnotetext{
${ }^{10}$ The data for other European countries are very incomplete. Where information is available, it is for a very short period of time.
} 
more disaggregated information on individual industries within Manufacturing. These are mainly two-digit industries, and include, for example, Textiles/Clothing and Chemicals. Again, full details are given in Appendix A.

The Regio dataset provides information on industry value-added and GDP by region, from which we compute the share of each sector in GDP. It also provides information on three broad factor endowments: total population, physical capital, and land area. ${ }^{11}$ These data are merged with information on educational attainment at the regional level from individual country labour force surveys. This enables us to disaggregate the population endowment into low, medium, and high education. The definitions we employ are standard in the labour market literature (see, for example, Nickell and Bell (1996) and Machin and Van Reenen (1998)). 'Low education' corresponds to no or primary qualifications, 'medium education' denotes secondary and/or vocational qualifications, and 'high education' is college degree or equivalent. ${ }^{12}$ We collect the data from the individual country labour force surveys in as consistent a manner as possible. The country or regional fixed effects included in the econometric estimation will also control for potential variation across countries in the classification of levels of educational attainment.

The length of the time-series available varies with the level of industrial aggregation, whether or not we use the information on educational attainment, and with the country considered. In order to exploit all of the information available, we consider two estimation samples. First, at the level of the three aggregate industries and for the three factor endowments (population, physical capital, and land area), we have an unbalanced panel of 811 observations per industry on the 45 regions during approximately 1975-95 (Sample A). Second, for the disaggregated manufacturing industries and for the 5 factor endowments (low education, medium education, high education, physical capital, and land area), we have an unbalanced panel of 696 observations per industry from approximately 1980 onwards (Sample B). Full details of the composition of each sample are given in Appendix A.

Table 1 presents information on the share of the three aggregate industries in each region's GDP in 1975,1985 , and 1995. We find substantial variation in patterns of production across regions at any one point in time, even at the level of the three aggregate industries. For example, the share of Agriculture in GDP in 1985 varies from 0.03\% in Be1 (Brussels) to 11.86\% in Esp4 (Centre), while the share of Services in GDP in 1985 varies from 81.61\% in Be1 (Brussels) to 49.57\% in Esp2 (North East). There are also marked changes in patterns of specialization over time. Thus, the share of Agriculture in GDP in Esp4 (Centre) falls from 14.72\% in 1980 to 5.39\% in 1995, while the share of Services in GDP in Fra3 (Nord-Pas-de-Calais) rises from 46.68\% in 1975 to $67.00 \%$ in 1995.

\footnotetext{
${ }^{11}$ We also experiment with using data on arable land area to control for variation in land quality.

${ }^{12}$ See Appendix A for further information concerning the data used.
} 
Table 2 analyses the evolution of the shares of the disaggregated manufacturing industries in GDP. For brevity, only the data for France and Spain are reported. Again, we observe substantial variation in patterns of production across regions at any one point in time. This is true both within and between countries. For example, the share of Metal Products and Machinery (Machine) in GDP in Fra7 (Centre-East) in 1985 is almost 3 times larger than that in Fra8 (Mediterranean) and almost 6 times larger than that in Esp6 (South). There are also changes in production patterns over time. The share of Chemicals in GDP in Esp6 (South) falls by 45\% between 1980 and 1994, while the share of Paper in FR3 (Nord-Pas-de-Calais) rises by $24 \%$ over the same period.

Table 3 examines variation in the three broad factor endowments (Population, Capital, and Land) across regions at a point in time and within regions over time. The sample includes both Uk5 (with a population of more than 16 million in 1985) and Luxembourg (with a population of just over 350,000 in 1985). Land area varies from around 16,000 hectares in Be1 (Brussels) to 21 million hectares in Es4 (Centre). While population declined in some regions, such as UK1 (North), it rose in others, such as UK6 (South-West). All regions exhibit an increase in the real stock of physical capital over time, although the rate of increase varies across regions.

In Table 4, we report regional educational attainment as a percentage of the population for the years 1985 and 1995. It is well known from the labour market literature that the sample period was one of rising educational attainment in European countries (see, for example Nickell and Bell (1996) and Machin and Van Reenen (1998)). With the exception of Be1 (Brussels), all regions in Table 4 experience a rise in the share of the population with high education during the sample period. However, the rate of increase varies substantially, even across regions even within a country. For example, in Esp2 (North-East) the high education share rises by over 70\%, while in the neighbouring region of Esp1 (North-West) the proportional rate of increase is approximately 40\%. Multiplying the percentage shares in Table 4 by the population levels reported in Table 3, we obtain regions' endowments of low, medium, and high education individuals.

\section{Econometric Specification}

Our main econometric equation is derived directly from the theoretical model of Section 2. From equation (4) we obtain,

$$
s_{z j t}=\beta_{0 j}+\sum_{k} \beta_{j k} \ln p_{z k t}+\sum_{i} \gamma_{j i} \ln v_{z i t}+\varepsilon_{z j t}
$$

where $\varepsilon_{z j t}$ is a stochastic error. We begin by assuming that this error is independently and identically distributed across regions and years. This assumption will be relaxed below where we consider a 
very general error components structure. Equation (6) is estimated separately for each industry $j$, pooling observations across regions $z$ and over time $t$. One problem in estimating this relationship using regional data is that measures of relative prices are not available for individual industries at the regional level. ${ }^{13}$ If relative prices are uncorrelated with factor endowments, it is still possible to consistently estimate the parameters $\gamma_{j i}$ as follows,

$$
(\mathbf{S P 1}) \quad s_{z j t}=\beta_{0 j}+\sum_{i} \gamma_{j i} \ln v_{z i t}+\varepsilon_{z j t}
$$

This is the first econometric specification that we consider (SP1), and is estimated separately for each industry using OLS. However, it is extremely implausible that regional relative prices will be uncorrelated with factor endowments. This is possible if all goods are perfectly tradeable and each region is a small open economy facing exogenous relative goods prices. If some goods are nontradeable and/or regions are large, $\mathrm{HO}$ theory itself predicts a correlation between regional relative prices and factor endowments. Therefore, subsequent econometric specifications explicitly control for relative prices.

In Specification 2 (SP2), we control for relative prices by assuming that all goods are perfectly tradeable. In this case, relative goods prices are the same across regions $\left(p_{z k t}=p_{k t}\right.$ for all $\left.z\right)$ and the second term of the right-hand-side of equation (6) may be replaced with a set of $\{0,1\}$ time dummies $\left(d_{j t}\right)$ in industry $j$,

$$
\text { (SP2) }
$$

$$
s_{z j t}=\beta_{0 j}+\phi_{j} \cdot d_{j t}+\sum_{i} \gamma_{j i} \ln v_{z i t}+\varepsilon_{z j t}
$$

where the time dummies also control for common macroeconomic shocks across regions in the error term $\varepsilon_{z j t}$.

The assumption that all goods are perfectly tradeable is strong. We are concerned with a general equilibrium relationship between a region's extent of specialization in industry $j$, relative prices, and factor endowments. This relationship includes the relative prices of all goods $k \in n, p_{k z t}$, and some goods (in particular, services) are likely to exhibit a degree of non-tradeability. Subsequent econometric specifications explicitly control for the existence of non-traded goods, and allow for more general forms of the error term $\varepsilon_{z j t}$. For example, as well as common macroeconomic shocks across regions, one might want to allow for a common error component across regions and time within a country or across time within individual regions.

\footnotetext{
${ }^{13}$ The left-hand-side of equation (6) is the share of current price value-added in current price GDP, which does not require information on regional-level relative prices.
} 
We begin by partitioning the full vector of goods prices $\left(p_{z t}\right)$ into the vectors of tradeable $\left(p_{z t}^{T}\right)$ and nontradeable goods $\left(p_{z t}^{N}\right)$ goods prices,

$$
p_{z t}^{\prime}=(\underbrace{p_{z t}^{T}}_{1 \times n^{T}}: \underbrace{p_{z t}^{N}}_{1 \times n^{N}})^{\prime}
$$

where $n=n^{T}+n^{N}$. Equation (6) may then be written as,

$$
s_{z j t}=\beta_{0 j}+\phi_{j} \cdot d_{j t}+\sum_{k=n^{T}+1}^{n} \beta_{j k} \ln p_{z k t}^{N}+\sum_{i} \gamma_{j i} \ln v_{z i t}+\varepsilon_{z j t}
$$

Following Harrigan (1997), we model unobserved non-traded goods prices as being drawn from an estimable probability distribution. Specification 3 models non-traded goods prices with a country fixed effect, time dummies, and an independently distributed stochastic error,

$$
\sum_{k=n^{T}+1}^{n} \beta_{j k} \ln p_{z k t}^{N}=\eta_{c j}+\mu_{j t}+u_{z j t}
$$

where $c$ indexes countries. Combining equations (9) and (10), we obtain,

(SP3)

$$
s_{z j t}=\beta_{0 j}+\eta_{c j}+\zeta_{j} \cdot d_{j t}+\sum_{i} \gamma_{j i} \ln v_{z i t}+\omega_{z j t}
$$

where $\omega_{z j t}=\varepsilon_{z j t}+u_{z j t}$. The country fixed effect $\left(\eta_{c j}\right)$ will also control for a common error component across regions and time within an individual country.

Specifications 4-5 are further generalizations of this approach. Specification 4 extends the model of non-traded goods prices by interacting the time dummies in (10) with country dummies. Equation (9) becomes,

$$
\text { (SP4) } \quad s_{z j t}=\beta_{0 j}+\xi_{j} \cdot d_{c j t}+\sum_{i} \gamma_{j i} \ln v_{z i t}+\omega_{z j t}
$$

where the country-time dummies $\left(d_{c j t}\right)$ control for a country-specific level and trend in relative goods prices over time. This specification allows increasing European integration to have different effects on relative prices in individual countries. The parameters of interest $\left(\gamma_{j i}\right)$ are now identified solely from variation in factor endowments across regions within a country. This includes both cross-section variation in factor endowments (across regions within a country at a point in time) and differential time-series variation in factor endowments (in individual regions within a country over time). ${ }^{14}$ As well as incorporating a more general model of non-traded goods prices, this specification therefore

\footnotetext{
${ }^{14}$ More precisely, the parameters of interest are identified from deviations in factor endowments from country-year means. The presence of the country-year dummies controls for any common trend in factor endowments across all regions within a country.
} 
allows us to abstract from cross-country differences and focus on the Heckscher-Ohlin model's ability to explain regional variation in patterns of production within countries.

Specification 5 allows for an even more general model of non-traded goods prices by including a regional fixed effect, country-time dummies and an independently distributed stochastic error,

$$
s_{z j t}=\beta_{0 j}+\eta_{z j}+\xi_{j} \cdot d_{c j t}+\sum_{i} \gamma_{j i} \ln v_{z i t}+\omega_{z j t}
$$

where the regional fixed effect $\left(\eta_{z j}\right)$ also controls for a common error component across time within an individual region. The parameters $\gamma_{j i}$ are now identified solely from differential time-series variation in factor endowments in individual regions within a country.

In estimating Specifications 1-5, we would like to observe an effect of factor endowments on patterns of production that is either robust across the different specifications or becomes clearer as we move to more general models of non-traded goods prices and more general forms of the error term $\varepsilon_{z j t}$. However, if our right-hand-side variables are measured with error, it is well known that the within groups transformation in (SP5) can greatly exacerbate the resulting attenuation bias. ${ }^{15}$ The extent of the 'within' or time-series variation in factor endowments due to variation in true unobserved factor endowments may be small relative to that due to measurement error. This is likely to be a particular problem in the present application, because the extent of the time-series variation in some of our factor endowments (in particular, land area and, to a lesser extent, population) is limited.

We address this problem in two ways. First, we exploit disaggregated data on the educational attainment of the population and on arable land area. The resulting measures of factor endowments control for cross-region variation in levels of skills and land quality, and exhibit greater differential variation over time within individual regions. Second, following Griliches and Hausman (1986), we consider the use of first-differenced estimators. The longer the interval of time over which we difference the data, the greater the amount of variation in true unobserved factor endowments relative to that due to measurement error. The attenuation bias due to measurement error should therefore be smaller using longer differences, and we analyze the results of 10-year difference estimators. Specification 6 is thus,

$$
\triangle_{10} s_{z j t}=\zeta_{j} \cdot d_{j t}+\sum_{i} \gamma_{j i} \triangle_{10} \ln v_{z i t}+\psi_{z j t}
$$

Before proceeding to the econometric estimation, a number of issues merit discussion. First, it is worth reiterating that, as we move between specifications, we change the source of variation in the

\footnotetext{
${ }^{15}$ See, in particular, Griliches and Hausman (1986).
} 
data that is used to identify the coefficients on factor endowments. In (SP1), the $\gamma_{j i}$ are identified from variation in factor endowments between countries, between regions within countries, and within regions over time. In (SP5), the $\gamma_{j i}$ are identified from differential variation in factor endowments over time in individual regions within a country.

Second, it is useful to relate the analysis here back to the earlier theoretical discussion of the $\mathrm{HO}$ and neoclassical models. In Section 2, we saw how country-industry-time technology differences could be incorporated into the neoclassical model, thereby modifying the equation for the share of an industry in a region's GDP (equation (5)). The country and regional fixed effects will respectively also control for any time-invariant differences in technology across countries and regions. Similarly, the country-industry time dummies will also control for any differences in the time path of technology levels across countries.

The third point has been already hinted at in the discussion above. By construction, the share of sector $j$ in GDP, $s_{z j t}$, is bounded between 0 and 100 per cent, and is $\mathrm{I}(0)$. However, in any finite sample, it may be I(1). This is particularly true of our sample period (1975-95), which, in general, is characterized by a secular decline in the shares of Agriculture and Manufacturing in GDP and a secular rise in the share of Services. Similarly, a region's population and physical capital endowments may be I(1). In this case, the static regressions (SP1)-(SP5) should be interpreted as cointegrating relationships between the share of a sector in GDP and factor endowments. Under this interpretation, the residuals should be $\mathrm{I}(0)$ if the $\mathrm{HO}$ model is a correct representation of the Data Generating Process (DGP). As is clear from a comparison of equations (4) and (5) in Section 2, this will not, in general, be true if there are time-varying region-industry technology parameters. These are excluded from the HO model by assumption and are not captured in specifications (SP1)-(SP5). A test for stationarity of the residuals is thus an important model specification test, and we make use of the panel data unit root test of Maddala and Wu (1999). ${ }^{16}$

Fourth, a key assumption of neoclassical trade theory is that the production technology is constant returns to scale. That is, neoclassical trade theory implies that the revenue function is homogeneous of degree 1 in factor endowments (equation (3)). In contrast, the new economic geography literature (see, in particular, Fujita, Krugman, and Venables (1999)) emphasizes the role of increasing returns to scale. A test that the revenue function is homogenous of degree $1\left(\sum_{i} \gamma_{j i}=0\right)$ therefore provides

\footnotetext{
${ }^{16}$ The Maddala and $\mathrm{Wu}$ or Fisher test statistic is based on the sum of the $P$-values from conventional Augmented Dickey Fuller (ADF) tests on the residuals for each cross-section unit $z \in Z$; it can be shown that $-2 \sum_{z} \ln P_{z}$ has a $\chi^{2}$ distribution with $2 Z$ degrees of freedom. This test statistic has a direct intuitive interpretation, is valid for unbalanced panels, and has attractive small sample properties (Maddala and $\mathrm{Wu}(1999)$ ). Other analyses of unit roots and cointegration in a panel data context include Im et al. (1997), Levin and Lin (1992), Pedroni (1999), Pesaran et al. (1998), and Quah (1994).
} 
another important model specification test.

Fifth, the estimated coefficients $\hat{\gamma}_{j i}$ correspond to general equilibrium effects of factor endowments on patterns of production. In the higher-dimensional Heckscher-Ohlin model with $n>2$ goods and $m>2$ factors of production, it is not possible to use information on factor intensities to make precise statements about the effects of a country's endowment of one factor of production on output in a particular industry. Nevertheless, since the theorems of the $2 \times 2 \times 2$ Heckscher-Ohlin model hold in a weakened form as averages or correlations,${ }^{17}$ we would expect a pattern of estimated coefficients across all industries taken together that is broadly consistent with information on factor intensity.

\section{Empirical Results}

Tables 5A-C report the results of estimating specifications (SP1)-(SP5) on the three aggregate (onedigit) industries for Sample A. We find a statistically significant relationship between factor endowments and regional patterns of production. ${ }^{18}$ The inclusion of year dummies and country fixed effects proves important in identifying this relationship - the pattern of estimated coefficients changes as we move from (SP1) to (SP3). This is exactly as one would expect if factor endowments are correlated with relative prices and if there is a common error component across all regions within a country that is correlated with factor endowments. In contrast, the pattern of estimated coefficients is extremely stable as one moves from (SP3) (country dummies and year dummies) to (SP4) (countryyear dummies). The second of these specifications corresponds most closely to the motivation in the introduction, in so far as it focuses on the relationship between patterns of production and factor endowments within countries.

The values of the estimated coefficients in (SP4) are generally consistent with economic priors. Population endowments are positively related to specialization in Services and negatively related to specialization in Manufacturing. Increased endowments of physical capital are associated with a higher share of Manufacturing in GDP and a lower share of Agriculture and Services. Land area is positively related to specialization in Agriculture and Manufacturing and negatively related to specialization in Services. With the exception of the coefficient on the population endowment in the regression for Agriculture, all estimated coefficients are statistically significant at the $5 \%$ level.

The pattern of estimated coefficients changes substantially when we include regional fixed effects in (SP5), and no longer has a plausible economic interpretation. For example, land area is negatively related to the share of Agriculture in GDP (though the relationship is not statistically significant),

\footnotetext{
${ }^{17}$ See, for example, the discussion in Dixit and Norman (1980), Chapter 4.

${ }^{18}$ Except where otherwise indicated, statements about statistical significance refer to the $5 \%$ level.
} 
while endowments of physical capital are positively and statistically significantly related to specialization in Agriculture. Since there is almost no time-series variation in land area (see Table 3), it is unclear how appropriate or meaningful this econometric specification is. The parameters of interest are being identified from deviations from time means, which in all cases are extremely small and in many cases are zero. It is plausible that the change in the estimated coefficients between (SP4) and (SP5) is largely driven by measurement error (see, for example, Griliches and Hausman (1986)). We investigate this possibility further below, where we disaggregate factor endowments (thereby introducing more time-series variation) and explore the results of long differences estimation.

Tables 5A-C also report the sum of the estimated coefficients on factor endowments in each industry and the results of a test whether the revenue function is linearly homogenous of degree 1 in factor endowments $\left(\sum_{i} \gamma_{j i}=0\right)$. Although the sum of the estimated coefficients is close to zero (often of order of magnitude $10^{-2}$ or smaller), the null hypothesis is frequently rejected at conventional levels of statistical significance, and is in fact rejected in all 3 industries in specifications (SP3) and (SP4). There is some evidence of increasing returns to scale in Manufacturing, where the sum of the estimated coefficients is strictly greater than zero in all specifications.

A second model specification test examines the stationarity of the residuals using the unit root tests of Maddala and Wu (1999). In most specifications, we are able to reject the null hypothesis of a unit root in the residuals in Agriculture and Manufacturing. For example, in Agriculture, it is only when we consider specification (SP1) that we are unable to reject this hypothesis. However, in Services, we are unable to reject the null hypothesis of a unit root in the residuals in specifications (SP1)-(SP4). Taken together, these results provide some evidence of model mis-specification, particularly in the Services sector. Two possible explanations for the non-stationarity of the Services' residuals are the omission of information on relevant factor endowments or the existence of time-varying region-industry technology differences (both of which will be included in the error term).

Table 6 investigates the first of these possibilities by introducing information on educational attainment and land quality. The availability of the educational attainment data reduces the sample size to 696 observations per industry (Sample B). ${ }^{19}$ For brevity, we only report the results for (SP4) and (SP5), and we begin by considering those in (SP4). The estimated coefficients on physical capital are very similar to those above, while the arable land coefficients resemble those estimated on total land area in Tables 5A-C. Endowments of physical capital are positively related to specialization in Manufacturing and negatively related to specialization in Agriculture and Services. Increased endowments of arable land are associated with a higher share of Agriculture and Manufacturing in

\footnotetext{
${ }^{19}$ The model in Tables 5A-C was re-estimated for the reduced sample; this yields very similar results to those reported in the paper.
} 
GDP, and a lower share of Services. All of these coefficients are statistically significant at the $5 \%$ level.

We find evidence of a statistically significant relationship between education endowments and a sector's share of GDP. Increased endowments of low-education labour are positively associated with specialization in Agriculture, while endowments of medium-education labour are negatively correlated with the share of this sector in GDP. Both coefficients are statistically significant at the $5 \%$ level. There is a positive and statistically significant relationship between endowments of mediumeducation labour and Manufacturing's share of GDP, while the relationship with endowments of high-education labour is negative and statistically significant. Endowments of high-education labour are positively linked with specialization in Services, while endowments of medium-education labour are negatively linked with the share of this sector in GDP. Both coefficients are statistically significant at the $5 \%$ level. This pattern of results is consistent with the idea that Services is skilled-labour intensive relative to Agriculture and Manufacturing.

The introduction of more disaggregated measures of factor endowments increases the regression $\mathrm{R}^{2}$. For example, in (SP4) in Manufacturing, this rises from 0.41 in Table 5B to 0.50 in Table 6 . We are now able to reject the null hypothesis of a unit root in the residuals at the $5 \%$ level in all three industries. This is consistent with the idea that the non-stationarity of the residuals in the specification with population, physical capital, and land area was due to the omission of information on relevant factor endowments. The sum of the estimated coefficients on factor endowments in all three industries is again close to zero, although the null hypothesis that the revenue function is linearly homogenous of degree 1 is rejected at the $5 \%$ level. The sum of the estimated coefficients in the Manufacturing sector remains strictly greater than zero, again providing some evidence of increasing returns to scale.

The introduction of regional fixed effects in (SP5) leads to a reduction in the absolute magnitude of most estimated coefficients. The sign of a number of estimated coefficients also changes, and these often no longer have a plausible economic interpretation. For example, increases in arable land area are negatively (though not statistically significantly) related to specialization in Agriculture. Again, it is plausible that these results are driven by measurement error - the reduction in the absolute magnitude of the estimated coefficients is particularly suggestive of attenuation bias. The extent of the 'within' or time-series variation due to variation in true unobserved factor endowments may be small relative to that due to measurement error. This is particularly true, for example, for arable land area. $^{20}$ Table 7 investigates this possibility further using the results of long differences estimation

\footnotetext{
${ }^{20}$ The extent of time-series variation in arable land area, though larger than that in total land area, remains small.
} 
over a 10-year time period (SP6). The long differences estimator enables us to control for unobserved heterogeneity at the regional level, while reducing the magnitude of any attenuation bias induced by measurement error. The pattern of estimated coefficients in Table 7 is similar to that reported in (SP4) of Table 6. For example, arable land area is positively and statistically significantly related to the share of Agriculture in GDP and negatively and statistically significantly related to the share of Services. The main exception is for the low education endowment, where one of the estimated coefficients changes sign.

The constancy of the estimated parameters as one moves from (SP3) to (SP4) in Tables 5A-C, the fact that (SP4) is explicitly concerned with variation in factor endowments across regions within a country, and the support provided by the results of long differences estimation, lead us to select (SP4) as our preferred specification. Throughout the remainder on the paper, we concentrate on the results using information on educational attainment and land quality. While the analysis so far has established the statistical significance of factor endowments in explaining patterns of production at the regional level, it has not established their quantitative importance. We investigate this issue by examining the model's within-sample prediction errors.

Table 8 reports mean shares of sectors in GDP and mean proportional prediction errors across regions and time for each country and industry. The mean prediction errors correspond to the mean across regions and time of the following variable: the absolute value of actual minus predicted shares of sectors in GDP, divided by actual shares $\left(\left|s_{z j t}-\hat{s}_{z j t}\right| / s_{z j t}\right)$. Predicted shares of sectors in GDP are calculated in two ways. First, we evaluate the fitted values from the regressions reported in Columns (1)-(3) of Table 6; these are indicated by the superscript 1 in Table 8 . Second, we evaluate predicted values from only those terms controlling for relative prices (ie excluding all factor endowments); these are indicated by the superscript 2. Existing studies using country-level data (Harrigan (1995)) and Japanese regional data (Bernstein and Weinstein (1998)) have focused on the Heckscher-Ohlin model's predictions for levels of output rather than for shares of GDP. To enable the results to be compared, it is straightforward to evaluate predicted output using the model. This is obtained simply by multiplying predicted shares by actual GDP, and the proportional prediction errors for output are identical to those reported for shares of sectors in GDP in Table 8.

The model's average prediction error in Manufacturing across all countries and years is $13 \%$, and varies from $6 \%$ in Belgium to $18 \%$ in the Netherlands. Factor endowments make a substantial contribution to explaining patterns of specialization across regions within countries. If we use the estimated coefficients to evaluate predicted shares of GDP excluding information on factor endowments, the average prediction error in Manufacturing across all countries and years rises to $49 \%$. 
Our measures of factor endowments are most successful at explaining regional patterns of production in Services and Manufacturing. Across regions in each country and with the sole exception of the Netherlands, we find the same ranking of industries in terms of (increasing) average prediction errors: from Services, through Manufacturing, to Agriculture. The average prediction error across all countries and years in Manufacturing (13\%) compares favorably with the average prediction error across disaggregated manufacturing industries in Harrigan (1995) using country-level data (38\%) and with the average prediction errors reported using regional data in Bernstein and Weinstein (1998).

One of the features that makes our sample period interesting is that it is one characterized by increasing European integration. In Table 9, we examine the magnitude of the model's prediction errors over time. Has the process of closer integration weakened the relationship between regions' patterns of production and their factor endowments, so that we observe an increase in average prediction errors over time? Since the country-year dummies in (SP4) control for any countryspecific changes in patterns of production, the analysis is explicitly concerned with how increasing integration affects the relationship between patterns of production and factor endowments within countries. From Table 9, we find no systematic increase or decrease in average prediction errors over time. Across all countries and years, the average prediction error falls in Services and remains broadly constant in Manufacturing and Agriculture.

Finally, it is frequently asserted that factor endowments explain specialization and trade at the aggregate level in industries such as Agriculture, Manufacturing, and Services, while other considerations, including imperfect competition and increasing returns to scale, are more important for specialization and trade within these aggregate industries. This hypothesis is implicit in the construction of theoretical models of inter and intra-industry trade, such as Krugman (1981), Helpman (1981), and Helpman and Krugman (1985). The same assumption is made in empirical work by Davis and Weinstein (1996), (1999). The present dataset and empirical framework may be used to shed light on whether this hypothesis holds for European regions. The model is estimated for individual disaggregated industries within the manufacturing sector, and the results are reported in Tables C1A and C1B of Appendix C. Factor endowments are found to play a statistically significant role in explaining patterns of production at the disaggregated level. For example, physical capital is positively and statistically significantly related to the share of Chemicals, Machinery, and Transport Equipment in a region's GDP. Medium education has a positive and statistically significant effect on specialization in Metals, Machinery, and Transport Equipment.

In Table 10, we examine the model's within-sample prediction errors at the disaggregated level. In 10 of the 11 manufacturing industries and for every 5-year period considered, the average within- 
sample prediction errors across countries, regions, and time are higher than those reported for manufacturing as a whole in Table 9 (the exception is the Construction industry). Considering all 11 disaggregated industries together, the average prediction error across countries, regions, and time during 1985-90 was 48\%. This compares with an average error across countries, regions, and time for the 3 aggregated industries in Table 9 of $31 \%$ over the same period. These results provide evidence that factor endowments are indeed more successful at explaining patterns production at the aggregate level (Agriculture, Manufacturing, and Services) than in disaggregated industries within the manufacturing sector.

The within-sample prediction errors for the disaggregated industries in Table 10 exhibit no systematic trend over time. Therefore, at the disaggregated level within manufacturing, we again find no evidence that the process of increasing European integration has weakened the relationship between factor endowments and patterns of production within countries. The null hypothesis that the residuals are $\mathrm{I}(1)$ is rejected in 10 of the 11 industries. Once information on educational attainment and land quality is incorporated into the analysis, there is again little evidence that the model is mis-specified in this regard. The sum of the estimated coefficients on factor endowments is, in most cases, close to 0, although the null hypothesis that the revenue function is linearly homogenous of degree 1 is rejected in all 11 disaggregated industries.

\section{Conclusions}

This paper has analyzed the relationship between patterns of production and factor endowments using data on a panel of 14 industries in 45 regions from 7 European countries since 1975 . We estimate a structural equation derived directly from Heckscher-Ohlin (HO) theory that relates the share of a sector in a region's GDP to factor endowments and relative prices. The use of European regional data enables us to abstract from many of the considerations that have been proposed as explanations for the disappointing empirical performance of HO theory at the country-level. At the same time, increasing economic integration introduces exogenous variation in relative prices, which we control for, and which means that Europe provides an interesting laboratory within which to explore the relationship between production patterns and factor endowments. In contrast to much existing empirical work on the international location of production, we explicitly consider both manufacturing and non-manufacturing sectors.

Across a wide range of different econometric specifications, there is a statistically significant relationship between factor endowments and patterns of production. Increases in physical capital are positively associated with Manufacturing's share of GDP and negatively associated with the share 
of Agriculture and Services. Movements from medium to high education are negatively related to specialization in Manufacturing and positively related to specialization in Services. These effects are quantitatively important: including information on factor endowments reduces the model's average within-sample percentage prediction error by around 350\%. Among the three aggregate industries considered, factor endowments are most successful at explaining regional specialization in Services and Manufacturing. Across regions within each country, we typically find the same ranking of industries in terms of (increasing) average prediction errors, from Services, through Manufacturing, to Agriculture. There is no evidence that the process of increasing economic integration in Europe has weakened the relationship between patterns of production and factor endowments across regions within countries.

There are clearly a large number of potential determinants of regional production patterns, including factor endowments, technology, and agglomeration economies. We find that the Heckscher-Ohlin model, with its emphasis on variation in factor endowments, provides a parsimonious and relatively successful explanation of European regional production patterns. Once information on educational attainment and land quality is incorporated in our measures of factor endowments, there is no evidence of non-stationarity in the model's residuals, as would be implied, for example, by time-varying region-industry technology differences. As frequently assumed in theoretical work, but rarely examined empirically, factor endowments are more successful at explaining specialization in aggregate industries (such as Agriculture, Manufacturing, and Services) than in disaggregated industries within the manufacturing sector (such as Chemicals and Machinery). 
Table 1: Shares of Agriculture, Manufacturing, and Services in GDP in

1975, 1985, and 1995 (percent) $^{(\mathrm{a})}$

\begin{tabular}{|c|c|c|c|c|c|c|c|c|c|}
\hline Region & Year & Agric & Manu & Serv & Region & Year & Agric & Manu & Serv \\
\hline \multirow[t]{3}{*}{$\overline{B e 1}$} & 1975 & 0.01 & 28.58 & 71.42 & \multirow[t]{3}{*}{ Fra7 } & 1975 & 4.30 & 46.46 & 49.24 \\
\hline & 1985 & 0.03 & 18.35 & 81.61 & & 1985 & 3.11 & 36.85 & 60.04 \\
\hline & 1995 & 0.02 & 15.75 & 84.23 & & 1995 & 2.43 & 32.17 & 65.40 \\
\hline \multirow[t]{3}{*}{$\mathrm{Be} 2$} & 1975 & 3.64 & 42.45 & $\overline{53.92}$ & \multirow[t]{3}{*}{ Fra8 } & 1975 & 5.98 & 32.96 & 61.06 \\
\hline & 1985 & 2.64 & 37.39 & 59.96 & & 1985 & 4.27 & 25.21 & 70.52 \\
\hline & 1995 & 1.52 & 34.27 & 64.21 & & 1995 & 3.24 & 20.26 & 76.51 \\
\hline \multirow[t]{3}{*}{ Be3 } & 1975 & 3.91 & 39.93 & 56.16 & \multirow[t]{3}{*}{ Ita1 } & 1975 & 4.46 & 48.20 & 47.34 \\
\hline & 1985 & 3.00 & 32.24 & 64.76 & & 1985 & 3.12 & 41.17 & 55.71 \\
\hline & 1995 & 1.76 & 27.36 & 70.88 & & 1995 & 2.42 & 36.87 & 60.71 \\
\hline \multirow[t]{3}{*}{ Esp1 } & 1980 & 9.35 & 39.22 & 51.43 & \multirow[t]{3}{*}{ Ita2 } & 1975 & 2.87 & 55.18 & 41.95 \\
\hline & 1985 & 8.07 & 39.29 & 52.64 & & 1985 & 2.05 & 45.49 & 52.45 \\
\hline & 1995 & 4.82 & 34.45 & 60.73 & & 1995 & 1.56 & 41.21 & 57.23 \\
\hline \multirow[t]{3}{*}{ Esp2 } & 1980 & 5.93 & 48.12 & 45.95 & \multirow[t]{3}{*}{ Ita3 } & 1975 & 6.03 & 45.82 & 48.15 \\
\hline & 1985 & 4.59 & 45.84 & 49.57 & & 1985 & 4.38 & 40.96 & 54.66 \\
\hline & 1995 & 2.25 & 42.12 & 55.63 & & 1995 & 3.13 & 36.71 & 60.17 \\
\hline \multirow[t]{3}{*}{ Esp3 } & 1980 & 0.55 & 30.58 & 68.86 & \multirow[t]{3}{*}{ Ita4 } & 1975 & 8.72 & 47.13 & 44.15 \\
\hline & 1985 & 0.32 & 28.61 & 71.08 & & 1985 & 5.75 & 40.87 & 53.38 \\
\hline & 1995 & 0.17 & 25.26 & 74.57 & & 1995 & 3.70 & 36.94 & 59.36 \\
\hline \multirow[t]{3}{*}{ Esp4 } & 1980 & 14.72 & 34.61 & 50.67 & \multirow[t]{3}{*}{ Ita5 } & 1975 & 5.32 & 45.34 & 49.34 \\
\hline & 1985 & 11.86 & 36.10 & 52.04 & & 1985 & 3.36 & 41.09 & 55.55 \\
\hline & 1995 & 5.39 & 34.50 & 60.11 & & 1995 & 2.64 & 34.62 & 62.75 \\
\hline \multirow[t]{3}{*}{ Esp5 } & 1980 & 4.24 & 42.19 & 53.56 & \multirow[t]{3}{*}{ Ita6 } & 1975 & 4.40 & 26.02 & 69.57 \\
\hline & 1985 & 3.00 & 39.44 & 57.56 & & 1985 & 2.59 & 25.09 & 72.32 \\
\hline & 1995 & 1.57 & 34.55 & 63.87 & & 1995 & 1.62 & 21.24 & 77.14 \\
\hline \multirow[t]{3}{*}{ Esp6 } & 1980 & 10.91 & 33.13 & 55.97 & \multirow[t]{3}{*}{ Ita7 } & 1975 & 10.70 & $\begin{array}{l}39.19 \\
\end{array}$ & 50.11 \\
\hline & & 10.84 & 29.25 & 59.91 & & 1985 & 6.72 & 34.32 & 58.95 \\
\hline & 1995 & 6.15 & 27.91 & 65.95 & & 1995 & 4.53 & 32.04 & 63.43 \\
\hline \multirow[t]{3}{*}{ Esp7 } & 1980 & 8.25 & 21.38 & 70.37 & \multirow[t]{3}{*}{ Ita8 } & 1975 & 10.26 & 31.29 & 58.45 \\
\hline & 1985 & 4.80 & 18.41 & 76.79 & & 1985 & 5.38 & 27.71 & 66.91 \\
\hline & 1995 & 2.06 & 18.56 & 79.38 & & 1995 & 3.33 & 24.30 & 72.36 \\
\hline Fra1 & 1975 & 0.68 & 34.87 & 64.45 & Ita9 & 1975 & 14.17 & $\begin{array}{l}31.02 \\
\end{array}$ & 54.81 \\
\hline & 1985 & 0.40 & 29.50 & 70.10 & & 1985 & 9.42 & 27.81 & 62.77 \\
\hline & 1995 & 0.18 & 22.54 & 77.28 & & 1995 & 6.49 & 24.49 & 69.02 \\
\hline$\overline{\text { Fra2 }}$ & 1975 & 8.73 & 43.58 & 47.69 & Itaa & 1975 & 12.56 & 29.54 & 57.90 \\
\hline & & 7.41 & 07 & 56.52 & & 1985 & 9.36 & 28.33 & 62.32 \\
\hline & 1995 & 4.27 & 32.69 & 63.04 & & 1995 & 5.73 & 21.47 & 72.80 \\
\hline Fra3 & 1975 & 4.04 & 49.28 & 46.68 & Itab & 1975 & 9.09 & 36.40 & 54.51 \\
\hline & 1985 & 2.62 & 35.80 & 61.58 & & 1985 & 5.96 & 33.64 & 60.39 \\
\hline & 1995 & 1.35 & 31.66 & 67.00 & & 1995 & 4.11 & 27.37 & 68.52 \\
\hline Fra4 & 1975 & 4.45 & 47.50 & 48.05 & Lux & 1975 & 3.24 & 39.18 & 57.57 \\
\hline & 1985 & 3.71 & 7.48 & 58.81 & & 1985 & 2.36 & 34.04 & 63.60 \\
\hline & 1995 & 2.60 & 34.66 & 62.74 & & 1995 & 1.21 & 31.61 & 67.19 \\
\hline Fra5 & 1975 & 11.38 & 37.48 & 51.14 & Nld1 & 1975 & 7.55 & 36.91 & 55.54 \\
\hline & 1985 & 7.98 & 29.24 & 62.78 & & 1985 & 4.33 & 35.08 & 60.58 \\
\hline & 1995 & 5.24 & 27.08 & 67.69 & & 1995 & 4.45 & 38.53 & 57.02 \\
\hline Fra6 & 1975 & 8.57 & 37.15 & 54.28 & Nld2 & 1975 & 7.24 & 35.21 & 57.55 \\
\hline & 1985 & 6.67 & 30.56 & 62.77 & & 1985 & 6.12 & 29.77 & 64.11 \\
\hline & 1995 & 4.41 & 24.37 & 71.22 & & 1995 & 4.19 & 27.24 & 68.58 \\
\hline
\end{tabular}


Table 1 (cont.): Shares of Agriculture, Manufacturing, and Services in GDP in 1975, 1985, and 1995 (percent) $^{(\mathrm{a})}$

\begin{tabular}{lllll|lllll}
\hline \hline Region & Year & Agric & Manu & Serv & Region & Year & Agric & Manu & Serv \\
\hline Nld3 & 1975 & 3.73 & 32.48 & 63.80 & Uk6 & 1975 & 3.27 & 36.86 & 59.87 \\
& 1985 & 3.29 & 28.23 & 68.48 & & 1980 & 3.23 & 35.60 & 61.17 \\
& 1995 & 2.71 & 23.64 & 73.65 & & 1985 & 2.16 & 34.36 & 63.48 \\
\hline Nld4 & 1975 & 4.70 & 43.21 & 52.09 & Uk7 & 1975 & 1.51 & 48.94 & 49.55 \\
& 1985 & 5.48 & 37.25 & 57.27 & & 1980 & 1.71 & 46.34 & 51.94 \\
& 1995 & 3.55 & 32.62 & 63.83 & & 1985 & 1.23 & 43.64 & 55.13 \\
\hline Uk1 & 1975 & 2.04 & 50.04 & 47.93 & Uk8 & 1975 & 0.87 & 45.53 & 53.60 \\
& 1980 & 1.58 & 47.29 & 51.12 & & 1980 & 0.70 & 45.46 & 53.84 \\
& 1985 & 1.37 & 41.37 & 57.25 & & 1985 & 0.53 & 44.32 & 55.15 \\
\hline Uk2 & 1975 & 2.31 & 46.46 & 51.23 & Uk9 & 1975 & 2.81 & 45.57 & 51.61 \\
& 1980 & 1.92 & 44.88 & 53.21 & & 1980 & 2.88 & 45.14 & 51.98 \\
& 1985 & 1.43 & 41.40 & 57.17 & & 1985 & 2.48 & 45.93 & 51.59 \\
\hline Uk3 & 1975 & 2.76 & 48.36 & 48.88 & Uka & 1975 & 2.98 & 43.73 & 53.28 \\
& 1980 & 2.76 & 46.45 & 50.79 & & 1980 & 2.39 & 42.17 & 55.44 \\
& 1985 & 1.59 & 44.29 & 54.11 & & 1985 & 1.69 & 38.82 & 59.49 \\
\hline Uk4 & 1975 & 6.56 & 36.12 & 57.32 & Ukb & 1975 & 3.40 & 43.37 & 53.23 \\
& 1980 & 5.78 & 35.93 & 58.29 & & 1980 & 3.30 & 37.21 & 59.49 \\
& 1985 & 3.07 & 36.02 & 60.91 & & 1985 & 2.89 & 36.00 & 61.11 \\
\hline Uk5 & 1975 & 0.82 & 32.14 & 67.03 & & & & & \\
& 1980 & 0.85 & 32.51 & 66.65 & & & & & \\
\hline \hline & 1985 & 0.48 & 29.46 & 70.06 & & & & & \\
\hline
\end{tabular}

Notes: (a) Figures may not sum to exactly 100 due to rounding. 
Table 2: Shares of the Disaggregated Manufacturing Industries in GDP in France and Spain in 1975, 1985, and 1995 (percent) $^{(\mathrm{a})}$

\begin{tabular}{|c|c|c|c|c|c|c|c|c|c|c|c|c|}
\hline$\overline{\overline{\text { Region }}}$ & $\overline{\text { Year }}$ & $\overline{\text { Fuel }}$ & Metal & Mineral & Chem & Machine & $\overline{\text { Transp }}$ & $\overline{\text { Food }}$ & $\overline{\text { Textile }}$ & $\overline{\text { Paper }}$ & $\overline{\text { Other }}$ & Constr \\
\hline \multirow[t]{3}{*}{ Esp1 } & 1980 & 7.47 & 5.61 & 2.13 & 1.34 & 3.49 & 2.82 & 4.20 & 0.74 & 0.54 & 1.69 & 9.19 \\
\hline & 1985 & 9.56 & 4.98 & 2.18 & 1.69 & 2.62 & 2.90 & 4.87 & 0.88 & 0.75 & 1.34 & 7.53 \\
\hline & 1994 & 7.84 & 2.63 & 1.92 & 0.79 & 2.34 & 2.19 & 4.53 & 0.69 & 0.51 & 1.08 & 9.06 \\
\hline \multirow[t]{3}{*}{ Esp2 } & 1980 & 4.52 & 5.14 & 2.12 & 1.96 & 12.65 & 3.01 & 5.00 & 1.55 & 2.01 & 4.11 & 6.05 \\
\hline & 1985 & 5.77 & 4.29 & 1.72 & 1.98 & 10.15 & 3.35 & 5.64 & 1.64 & 1.97 & 3.63 & 5.70 \\
\hline & 1994 & 7.00 & 2.11 & 1.69 & 1.10 & 8.82 & 3.28 & 4.59 & 0.95 & 1.45 & 2.52 & 6.83 \\
\hline \multirow[t]{3}{*}{ Esp3 } & 1980 & 1.14 & 0.60 & 1.21 & 2.71 & 7.27 & 2.54 & 2.67 & 1.32 & 1.32 & 1.66 & 7.72 \\
\hline & 1985 & 2.27 & 0.24 & 0.89 & 2.76 & 6.00 & 2.09 & 3.08 & 1.54 & 2.11 & 1.57 & 6.06 \\
\hline & 1994 & 2.41 & 0.16 & 0.77 & 1.75 & 4.28 & 1.76 & 2.09 & 0.78 & 2.01 & 1.04 & 8.14 \\
\hline \multirow[t]{3}{*}{ Esp4 } & 1980 & 6.16 & 0.41 & 2.06 & 1.41 & 2.30 & 3.74 & 5.11 & 1.57 & 0.58 & 2.29 & 8.98 \\
\hline & 1985 & 9.86 & 0.33 & 1.87 & 1.67 & 1.97 & 2.78 & 5.65 & 1.80 & 0.74 & 1.92 & 7.50 \\
\hline & 1994 & 9.50 & 0.17 & 1.80 & 1.10 & 1.88 & 2.11 & 4.76 & 1.21 & 0.52 & 1.54 & 9.85 \\
\hline \multirow[t]{3}{*}{ Esp5 } & 1980 & 3.41 & 0.61 & 2.37 & 3.41 & 6.09 & 2.72 & 4.35 & 6.49 & 1.50 & 3.24 & 8.01 \\
\hline & 1985 & 4.83 & 0.42 & 2.22 & 3.47 & 5.58 & 2.05 & 4.99 & 5.54 & 1.52 & 2.88 & 5.94 \\
\hline & 1994 & 4.80 & 0.21 & 1.86 & 2.67 & 4.53 & 1.75 & 3.97 & 3.39 & 1.38 & 2.34 & 6.94 \\
\hline \multirow[t]{3}{*}{ Esp6 } & 1980 & 5.69 & 1.14 & 2.61 & 1.39 & 1.89 & 1.71 & 5.94 & 1.32 & 0.56 & 1.07 & 9.81 \\
\hline & 1985 & 4.80 & 1.41 & 1.38 & 2.24 & 1.68 & 1.45 & 6.65 & 1.33 & 0.62 & 0.88 & 6.80 \\
\hline & 1994 & 6.04 & 0.61 & 1.14 & 0.77 & 1.34 & 1.09 & 5.07 & 0.79 & 0.46 & 0.73 & 8.67 \\
\hline \multirow[t]{3}{*}{ Esp7 } & 1980 & 3.36 & 0.00 & 1.08 & 0.38 & 0.53 & 0.18 & 4.63 & 0.09 & 0.72 & 0.53 & 9.89 \\
\hline & 1985 & 4.18 & 0.01 & 0.86 & 0.24 & 0.63 & 0.31 & 3.05 & 0.31 & 0.59 & 0.70 & 7.53 \\
\hline & 1994 & 5.12 & 0.03 & 0.79 & 0.13 & 0.42 & 0.29 & 3.10 & 0.17 & 0.49 & 0.40 & 7.36 \\
\hline \multirow[t]{3}{*}{ Fra1 } & 1980 & 4.48 & 0.87 & 0.64 & 2.52 & 7.88 & 4.47 & 2.26 & 1.08 & 1.80 & 1.16 & 5.61 \\
\hline & 1985 & 5.56 & 0.70 & 0.55 & 2.52 & 7.11 & 2.49 & 1.63 & 0.95 & 2.21 & 1.03 & 4.73 \\
\hline & 1994 & 5.06 & 0.28 & 0.49 & 2.01 & 4.78 & 1.87 & 1.41 & 0.70 & 2.36 & 0.72 & 4.04 \\
\hline \multirow[t]{3}{*}{ Fra2 } & 1980 & 3.89 & 1.42 & 1.57 & 2.81 & 9.96 & 3.93 & 6.08 & 2.05 & 1.31 & 2.82 & 6.73 \\
\hline & 1985 & 5.47 & 1.09 & 1.18 & 2.26 & 8.07 & 2.20 & 4.68 & 1.79 & 1.46 & 2.51 & 5.35 \\
\hline & 1994 & 4.57 & 0.88 & 1.14 & 2.46 & 7.62 & 2.68 & 3.59 & 1.16 & 1.46 & 2.62 & 4.99 \\
\hline \multirow[t]{3}{*}{ Fra3 } & 1980 & 5.47 & 4.00 & 2.36 & 2.80 & 7.38 & 3.77 & 5.43 & 5.34 & 1.46 & 1.31 & 6.82 \\
\hline & 1985 & 4.69 & 2.59 & 1.99 & 1.73 & 5.47 & 2.35 & 4.10 & 4.71 & 1.67 & 1.23 & 5.28 \\
\hline & 1994 & 3.06 & 2.55 & 1.65 & 2.49 & 4.41 & 2.29 & 4.23 & 2.54 & 1.81 & 1.48 & 4.58 \\
\hline \multirow[t]{3}{*}{ Fra4 } & 1980 & 3.65 & 3.86 & 1.77 & 2.52 & 9.27 & 5.48 & 4.71 & 2.66 & 1.49 & 2.45 & 6.62 \\
\hline & 1985 & 3.34 & 2.41 & 1.55 & 1.98 & 8.28 & 4.26 & 4.03 & 2.44 & 1.67 & 2.48 & 5.04 \\
\hline & 1994 & 2.71 & 1.39 & 1.18 & 1.65 & 7.81 & 5.24 & 3.78 & 1.35 & 1.76 & 2.58 & 4.98 \\
\hline \multirow[t]{3}{*}{ Fra5 } & 1980 & 3.22 & 0.38 & 1.31 & .75 & 6.34 & 4.17 & 6.73 & 2.25 & 1.09 & 2.42 & 8.71 \\
\hline & 1985 & 2.85 & 0.34 & 0.95 & 0.73 & 5.40 & 2.50 & 4.99 & 1.94 & 1.22 & 2.46 & 5.85 \\
\hline & 1994 & 2.46 & 0.20 & 0.95 & 0.68 & 5.34 & 2.57 & 5.04 & 1.19 & 1.30 & 2.49 & 5.34 \\
\hline \multirow[t]{3}{*}{ Fra6 } & 1980 & 6.99 & 0.63 & 1.50 & 2.36 & 4.61 & 2.93 & 4.09 & 2.39 & 1.31 & 1.85 & 7.52 \\
\hline & 1985 & 6.94 & 0.56 & 1.09 & 1.30 & 4.16 & 2.33 & 3.27 & 1.98 & 1.35 & 1.64 & 5.93 \\
\hline & 1994 & 3.74 & 0.21 & 1.02 & 1.15 & 4.05 & 2.47 & 3.35 & 0.99 & 1.24 & 1.76 & 5.16 \\
\hline \multirow[t]{3}{*}{ Fra7 } & 1980 & 3.57 & 1.55 & 1.29 & 2.64 & 12.06 & 2.96 & 3.60 & 2.96 & 1.44 & 4.00 & 7.43 \\
\hline & 1985 & 4.18 & 1.09 & 1.05 & 2.39 & 9.83 & 1.61 & 2.94 & 2.46 & 1.37 & 3.69 & 6.22 \\
\hline & 1994 & 4.02 & 1.00 & .87 & 2.16 & 8.86 & 1.43 & 2.69 & 1.83 & 1.27 & 3.27 & 5.41 \\
\hline \multirow[t]{3}{*}{ Fra8 } & 1980 & 4.41 & 1.85 & 1.41 & 1.90 & 3.32 & 1.59 & 3.70 & 0.82 & 0.68 & 0.92 & 9.12 \\
\hline & 1985 & 5.42 & 1.51 & 1.14 & 1.31 & 3.53 & 1.28 & 2.36 & 0.59 & 0.78 & 0.88 & 6.42 \\
\hline & 1994 & 4.22 & 0.86 & .89 & 1.55 & 2.80 & 0.99 & 2.17 & 0.37 & 0.75 & 0.83 & 5.35 \\
\hline
\end{tabular}

(a) See Appendix A for industry definitions. 
Table 3: Factor Endowments in 1975, 1985, and 1995(a)

\begin{tabular}{|c|c|c|c|c|c|c|c|c|c|}
\hline Region & Year & Pop & Cap & Land & Region & Year & Pop & Cap & Land \\
\hline \multirow[t]{3}{*}{ Be1 } & 1975 & 967.38 & 6721.539 & 16.2 & \multirow[t]{3}{*}{ Fra7 } & 1975 & 5884.79 & 87949.34 & 7113.6 \\
\hline & 1985 & 961.1 & 7945.636 & 16.1 & & 1985 & 6388.3 & 131157.8 & 7113.6 \\
\hline & 1995 & 944.9 & 9068.479 & 16.1 & & 1995 & 6765.8 & 154844.7 & 7113.6 \\
\hline \multirow[t]{3}{*}{$\overline{\mathrm{Be} 2}$} & 1975 & 5400.21 & 11579.08 & 1351.1 & \multirow[t]{3}{*}{ Fra8 } & 1975 & 5240.18 & 57037.51 & 6828.2 \\
\hline & 1985 & 5646.7 & 21646.15 & 1351.2 & & 1985 & 5627.4 & 96296.46 & 6828.2 \\
\hline & 1995 & 5852 & 37943.63 & 1351.2 & & 1995 & 6775.3 & 124957.2 & 6828.2 \\
\hline \multirow[t]{3}{*}{ Be3 } & 1975 & 3160.45 & 6758.029 & 1684.8 & \multirow[t]{3}{*}{ Ita1 } & 1975 & 6431.26 & 65155.07 & 3407.6 \\
\hline & 1985 & 3197.8 & 9619.443 & 1684.4 & & 1985 & 6199 & 101068 & 3407.7 \\
\hline & 1995 & 3307.9 & 14563.69 & 1684.4 & & 1995 & 5978.6 & 131306.6 & 3407.9 \\
\hline \multirow{3}{*}{ Esp1 } & 1975 & 4210.96 & 27446.6 & 4528.8 & \multirow[t]{3}{*}{ Ita2 } & 1975 & 8665.99 & 94042.59 & 2385.03 \\
\hline & 1985 & 4443 & 39729.87 & 4532.8 & & 1985 & 8752.7 & 154774.1 & 2385.7 \\
\hline & 1995 & 4298 & 54444.34 & 4536.2 & & 1995 & 8786.7 & 202913.6 & 2387.3 \\
\hline \multirow[t]{3}{*}{ Esp2 } & 1975 & 3855.28 & 34242.75 & 7037.4 & \multirow[t]{3}{*}{ Ita3 } & 1975 & 6229.93 & 67239.92 & 3982.47 \\
\hline & 1985 & 4088.35 & 44469.33 & 7038.6 & & 1985 & 6344.9 & 109107.3 & 3983.1 \\
\hline & 1995 & 3993.6 & 63817.2 & 7034.3 & & 1995 & 6407.3 & 147813.5 & 3982.7 \\
\hline \multirow[t]{3}{*}{ Esp3 } & 1975 & 4345.41 & 31732.97 & 799.5 & \multirow[t]{3}{*}{ Ita4 } & 1975 & 3864.12 & 38671.77 & 2212.3 \\
\hline & 1985 & 4824.05 & 39215.81 & 799.5 & & 1985 & 3893.2 & 65189.58 & 2212.3 \\
\hline & 1995 & 5040.40 & 65441.33 & 802.8 & & 1995 & 3866.7 & 82760.49 & 2212.3 \\
\hline \multirow[t]{3}{*}{ Esp4 } & 1975 & 4947.70 & 33809.81 & 21492.3 & \multirow[t]{3}{*}{ Ita5 } & 1975 & 5642.75 & 53216.01 & 4114.13 \\
\hline & 1985 & 5217.08 & 54417.75 & 21483.5 & & 1985 & 5750.3 & 88498.08 & 4114.2 \\
\hline & 1995 & 5170.5 & 74640.4 & 21483.6 & & 1995 & 5714 & 105956 & 4114.2 \\
\hline \multirow[t]{3}{*}{ Esp5 } & 1975 & 9490.14 & 83441.64 & 6020.5 & \multirow[t]{3}{*}{ Ita6 } & 1975 & 4823.32 & 37194.79 & 1720.3 \\
\hline & 1985 & 10169.84 & 108768.1 & 6013.4 & & 1985 & 5008.7 & 70660.65 & 1720.3 \\
\hline & 1995 & 10594.5 & 169036.2 & 6014.8 & & 1995 & 5099.1 & 115990.2 & 1720.3 \\
\hline \multirow[t]{3}{*}{ Esp6 } & 1975 & 6667.77 & 38905.89 & 9858.5 & \multirow[t]{3}{*}{ Ita7 } & 1975 & 1494.95 & 16654.18 & 1523.2 \\
\hline & 1985 & 7449.77 & 59331.64 & 9858.7 & & 1985 & 1555.7 & 26232.84 & 1523.2 \\
\hline & 1995 & 8197.3 & 93269.52 & 9867.6 & & 1995 & 1579.2 & 30796.81 & 1523.2 \\
\hline \multirow[t]{3}{*}{ Esp7 } & 1975 & 1229.36 & 7540.541 & 746.6 & \multirow[t]{3}{*}{ Ita8 } & 1975 & 5147.29 & 31031.16 & 1359.5 \\
\hline & 1985 & 1389.59 & 11781.26 & 750 & & 1985 & 5557.1 & 59298.32 & 1359.5 \\
\hline & 1995 & 1521.4 & 20202.67 & 748 & & 1995 & 5687.1 & 74722.96 & 1359.5 \\
\hline Fra1 & 1975 & 9899.95 & 177317.3 & 1196.5 & Ita9 & 1975 & 6255.12 & 44407.48 & 4442 \\
\hline & 1985 & 10345.2 & 272393.2 & 1196.5 & & 1985 & 6620.9 & 75853.26 & 4442 \\
\hline & 1995 & 10703.7 & 396078.6 & 1196.5 & & 1995 & 6654.6 & 91471.69 & 4442 \\
\hline Fra2 & 1975 & 8877.92 & 147434.4 & 14659.9 & Itaa & 1975 & 4739.18 & 28564.2 & 2570.8 \\
\hline & 1985 & 9452.4 & 206561.2 & 14659.9 & & 1985 & 4973 & 54135.88 & 2570.8 \\
\hline & 1995 & 9888.5 & 231949.6 & 14659.9 & & 1995 & 5000.3 & 67786.23 & 2570.9 \\
\hline Fra3 & 1975 & 3854.59 & 40983.74 & 1245.1 & Itab & 1975 & 1504.68 & 14526.73 & 2409 \\
\hline & 1985 & 3910.9 & 61957.58 & 1245.1 & & 1985 & 1607.2 & 24124.79 & 2409 \\
\hline & 1995 & 3821.9 & 73979.1 & 1245.1 & & 1995 & 1639.9 & 30440.95 & 2409 \\
\hline Fra4 & 1975 & 4694.08 & 77341.84 & 4830.9 & Lux & 1975 & 351.73 & 5928.26 & 258.6 \\
\hline & 1985 & 4670.8 & 108023.8 & 4830.9 & & 1985 & 355.9 & 8309.376 & 258.6 \\
\hline & 1995 & 4858.4 & 123198 & 4830.9 & & 1995 & 402.5 & 13997.32 & 256.8 \\
\hline Fra5 & 1975 & 6465.02 & 83522.45 & 8585.6 & Nld1 & 1975 & 1465.86 & 18254.55 & 904.5 \\
\hline & 1985 & 6927.4 & 124273 & 8585.6 & & 1985 & 1553.87 & 29099.54 & 1070 \\
\hline & 1995 & 7589.1 & 148911.2 & 8585.6 & & 1995 & 1593.9 & 37060.6 & 1138.8 \\
\hline$\overline{\text { Fra6 }}$ & 1975 & 5014.20 & 75540.89 & 10449 & $\overline{\text { Nld2 }}$ & 1975 & 2579.9 & 26835.04 & 1021.1 \\
\hline & 1985 & 5607.2 & 108094.2 & 10449 & & 1985 & 2877.51 & 45296.34 & 1020.1 \\
\hline & 1995 & 5932.9 & 120266 & 10449 & & 1995 & 3129.4 & 61913.82 & 1097.6 \\
\hline
\end{tabular}

(a) See Appendix A for further details concerning the factor endowments used. 
Table 3 (cont.): Factor Endowments in 1975, 1985, and 1995(a)

\begin{tabular}{lllll|lllll}
\hline \hline Region & Year & Pop & Cap & Land & Region & Year & Pop & Cap & Land \\
\hline Nld3 & 1975 & 6351.84 & 75012.2 & 1037.8 & Uk6 & 1975 & 4162.70 & 16877.93 & 2383 \\
& 1985 & 6597.38 & 125395.7 & 1123.5 & & 1985 & 4407.4 & 28854.15 & 2385 \\
& 1995 & 7099.5 & 167428.8 & 1187.1 & & 1995 & 4711.5 & 37562.04 & 2385 \\
\hline Nld4 & 1975 & 2925.58 & 33294.7 & 731.4 & Uk7 & 1975 & 5133.62 & 15359.96 & 1301.3 \\
& 1985 & 3124.39 & 53328.02 & 731.5 & & 1985 & 5127.5 & 27263.04 & 1301.3 \\
& 1995 & 3350.2 & 74382.43 & 729.1 & & 1995 & 5231.8 & 39124.63 & 1301.3 \\
\hline Uk1 & 1975 & 3125.56 & 13258.54 & 1540.03 & Uk8 & 1975 & 6498.89 & 21552.36 & 731.43 \\
& 1985 & 3051.7 & 21612.87 & 1540.1 & & 1985 & 6305.7 & 35511.66 & 733.1 \\
& 1995 & 3055.2 & 27599.95 & 1542.1 & & 1995 & 6323.1 & 48322.58 & 734.4 \\
\hline Uk2 & 1975 & 4876.12 & 20716 & 1541.8 & Uk9 & 1975 & 2764.09 & 6902.181 & 2076.6 \\
& 1985 & 4845.4 & 32875.4 & 1542 & & 1985 & 2777.3 & 13993.15 & 2076.8 \\
& 1995 & 4959.2 & 41394.54 & 1542.1 & & 1995 & 2868.2 & 22284.25 & 2076.6 \\
\hline Uk3 & 1975 & 3728.18 & 14490.71 & 1561 & Uka & 1975 & 5122.10 & 21536.84 & 7877.13 \\
& 1985 & 3851.7 & 24247.27 & 1563 & & 1985 & 5052.3 & 33158.39 & 7878.3 \\
& 1995 & 4063.6 & 34597.66 & 1563 & & 1995 & 5051 & 43721.04 & 7878.3 \\
\hline Uk4 & 1975 & 1763.64 & 11419.7 & 1256.57 & Ukb & 1975 & 1519.85 & 6602.664 & 1412.07 \\
& 1985 & 1934.1 & 17298.85 & 1257.3 & & 1985 & 1535.1 & 10267.07 & 1412 \\
& 1995 & 2092 & 19389.3 & 1257.3 & & 1995 & 1598.8 & 13058.63 & 1412.2 \\
\hline Uk5 & 1975 & 16688.35 & 87776.61 & 2722.27 & & 1975 & & & \\
& 1985 & 16880.9 & 134179.3 & 2722.2 & & 1985 & & & \\
& 1995 & 17570.2 & 155221.4 & 2722.7 & & 1995 & & & \\
\hline \hline
\end{tabular}

(a) See Appendix A for further details concerning the factor endowments used. 
Table 4: Educational Attainment by Region in 1985 and 1995 (percentage of total population)(a)

\begin{tabular}{|c|c|c|c|c|c|c|c|c|c|}
\hline Region & Year & Low & Med & High & Region & Year & Low & Med & High \\
\hline \multirow[t]{2}{*}{$\mathrm{Be1}$} & 1985 & 53.35 & 41.55 & 5.10 & Ita6 & 1985 & 60.43 & 29.38 & 9.41 \\
\hline & 1995 & 35.97 & 59.68 & 4.35 & & 1995 & 46.34 & 39.99 & 13.67 \\
\hline \multirow[t]{2}{*}{ Be2 } & 1985 & 50.97 & 45.35 & 3.67 & Ita7 & 1985 & 71.65 & 21.99 & 6.30 \\
\hline & 1995 & 41.90 & 52.51 & 5.59 & & 1995 & 56.26 & 34.15 & 9.59 \\
\hline \multirow[t]{2}{*}{ Be3 } & 1985 & 51.07 & 45.27 & 3.66 & Ita8 & 1985 & 73.40 & 19.98 & 6.71 \\
\hline & 1995 & 37.49 & 57.20 & 5.31 & & 1995 & 57.98 & 31.73 & 10.29 \\
\hline \multirow[t]{2}{*}{ Esp1 } & 1985 & 65.31 & 28.52 & 6.18 & Ita9 & 1985 & 73.91 & 20.45 & 5.72 \\
\hline & 1995 & 44.46 & 46.94 & 8.60 & & 1995 & 60.67 & 29.67 & 9.67 \\
\hline \multirow[t]{2}{*}{ Esp2 } & 1985 & 59.83 & 32.45 & 7.72 & Itaa & 1985 & 70.94 & 21.73 & 7.26 \\
\hline & 1995 & 38.35 & 48.30 & 13.34 & & 1995 & 59.83 & 30.07 & 10.10 \\
\hline \multirow[t]{2}{*}{ Esp3 } & 1985 & 47.22 & 40.70 & 12.08 & Itab & 1985 & 77.40 & 17.16 & 5.79 \\
\hline & 1995 & 33.51 & 50.17 & 16.32 & & 1995 & 65.70 & 27.35 & 6.96 \\
\hline \multirow[t]{2}{*}{ Esp4 } & 1985 & 67.42 & 26.44 & 6.14 & Lux & 1985 & 51.07 & 45.27 & 3.66 \\
\hline & 1995 & 48.11 & 42.43 & 9.46 & & 1990 & 37.49 & 57.20 & 5.31 \\
\hline \multirow[t]{2}{*}{ Esp5 } & 1985 & 67.42 & 30.49 & 6.13 & Nld1 & 1985 & 29.75 & 62.33 & 9.03 \\
\hline & 1995 & 39.36 & 50.94 & 9.71 & & 1995 & 14.86 & 68.53 & 16.79 \\
\hline \multirow[t]{2}{*}{ Esp6 } & 1985 & 70.07 & 24.53 & 5.39 & Nld2 & 1985 & 27.76 & 62.77 & 9.33 \\
\hline & 1995 & 49.28 & 43.28 & 7.45 & & 1995 & 14.53 & 68.48 & 16.95 \\
\hline \multirow[t]{2}{*}{ Esp7 } & 1985 & 65.39 & 28.19 & 6.42 & Nld3 & 1985 & 28.33 & 58.68 & 12.02 \\
\hline & 1995 & 43.66 & 46.23 & 10.11 & & 1995 & 14.80 & 62.88 & 22.12 \\
\hline \multirow[t]{2}{*}{ Fra1 } & 1985 & 46.13 & 34.18 & 19.44 & Nld4 & 1985 & 29.06 & 61.16 & 9.47 \\
\hline & 1994 & 36.50 & 40.50 & 23.00 & & 1995 & 15.08 & 67.58 & 17.08 \\
\hline \multirow[t]{2}{*}{ Fra2 } & 1985 & 61.95 & 35.98 & 9.36 & Uk1 & 1985 & 40.48 & 44.32 & 3.18 \\
\hline & 1994 & 40.00 & 38.50 & 21.50 & & 1994 & 25.51 & 68.37 & 5.80 \\
\hline \multirow[t]{2}{*}{ Fra3 } & 1985 & 65.91 & 35.08 & 7.92 & Uk2 & 1985 & 38.39 & 46.85 & 3.56 \\
\hline & 1994 & 49.00 & 38.50 & 12.50 & & 1994 & 24.42 & 68.10 & 7.14 \\
\hline \multirow[t]{2}{*}{ Fra4 } & 1985 & 55.36 & 38.68 & 10.80 & Uk3 & 1985 & 34.89 & 47.15 & 4.43 \\
\hline & 1994 & 40.50 & 44.00 & 15.50 & & 1994 & 24.81 & 67.38 & 7.60 \\
\hline \multirow[t]{2}{*}{ Fra5 } & 1985 & 55.36 & 38.68 & 10.08 & Uk4 & 1985 & 36.31 & 48.60 & 4.66 \\
\hline & 1994 & 40.00 & 45.00 & 15.00 & & 1994 & 21.79 & 70.63 & 7.49 \\
\hline \multirow[t]{2}{*}{ Fra6 } & 1985 & 48.77 & 40.48 & 12.96 & Uk5 & 1985 & 27.98 & 53.17 & 7.41 \\
\hline & 1994 & 35.50 & 46.00 & 18.50 & & 1994 & 19.44 & 68.50 & 11.71 \\
\hline \multirow[t]{2}{*}{ Fra7 } & 1985 & 50.09 & 39.58 & 13.68 & Uk6 & 1985 & 41.86 & 40.71 & 4.06 \\
\hline & 1994 & 36.32 & 44.28 & 19.40 & & 1994 & 20.90 & 70.24 & 8.63 \\
\hline \multirow[t]{2}{*}{ Fra8 } & 1985 & 56.68 & 36.88 & 12.24 & Uk7 & 1985 & 34.77 & 47.92 & 4.14 \\
\hline & 1994 & 41.79 & 41.29 & 16.92 & & 1994 & 27.67 & 64.79 & 7.07 \\
\hline \multirow[t]{2}{*}{ Ita1 } & 1985 & 73.54 & 21.43 & 5.06 & Uk8 & 1985 & 37.25 & 47.46 & 4.26 \\
\hline & 1995 & 56.55 & 34.64 & 8.81 & & 1994 & 25.09 & 66.89 & 7.77 \\
\hline \multirow[t]{2}{*}{ Ita2 } & 1985 & 74.03 & 20.84 & 5.21 & Uk9 & 1985 & 43.44 & 43.44 & 5.10 \\
\hline & 1995 & 54.46 & 35.32 & 10.22 & & 1994 & 26.15 & 66.20 & 7.54 \\
\hline \multirow[t]{2}{*}{ Ita3 } & 1985 & 77.29 & 18.46 & 4.54 & Uka & 1985 & 55.00 & 39.80 & 3.81 \\
\hline & 1995 & 56.92 & 35.54 & 7.54 & & 1994 & 20.30 & 70.60 & 8.86 \\
\hline Ita4 & 1985 & 71.98 & 22.00 & 5.97 & Ukb & 1985 & 55.62 & 39.18 & 3.97 \\
\hline & 1995 & 54.89 & 35.79 & 9.33 & & 1994 & 35.40 & 56.13 & 8.05 \\
\hline Ita5 & 1985 & 73.19 & 21.36 & 5.47 & & & & & \\
\hline & 1995 & 56.84 & 34.02 & 9.14 & & & & & \\
\hline
\end{tabular}

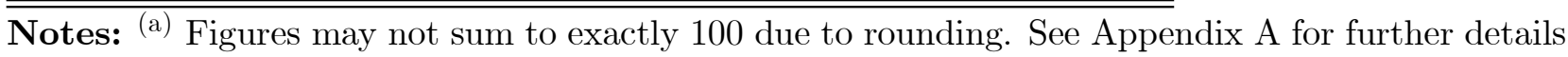
concerning the data used. 
Table 5A: Factor Endowments and Specialization in Agriculture

\begin{tabular}{|c|c|c|c|c|c|}
\hline$s_{z j t}$ & (1) & $(2)$ & $(3)$ & (4) & $(5)$ \\
\hline Obs & 811 & 811 & 811 & 811 & 811 \\
\hline Years & $1975-95$ & $1975-95$ & $1975-95$ & $1975-95$ & $1975-95$ \\
\hline Capital $_{z t}$ & $\begin{array}{l}-0.002 \\
(0.0012)\end{array}$ & $\begin{array}{l}0.004^{* *} \\
(0.0013)\end{array}$ & $\begin{array}{l}-0.022^{* *} \\
(0.0035)\end{array}$ & $\begin{array}{l}-0.019^{* *} \\
(0.0037)\end{array}$ & $\begin{array}{l}0.010^{* *} \\
(0.0037)\end{array}$ \\
\hline Population $_{z t}$ & $\begin{array}{l}-0.016^{* *} \\
(0.0018)\end{array}$ & $\begin{array}{l}-0.021^{* *} \\
(0.0018)\end{array}$ & $\begin{array}{l}0.002 \\
(0.0040)\end{array}$ & $\begin{array}{l}-0.002 \\
(0.0042)\end{array}$ & $\begin{array}{l}-0.117^{* *} \\
(0.0136)\end{array}$ \\
\hline $\operatorname{Land}_{z t}$ & $\begin{array}{l}0.017^{* *} \\
(0.0008)\end{array}$ & $\begin{array}{l}0.017^{* *} \\
(0.0008)\end{array}$ & $\begin{array}{l}0.016^{* *} \\
(0.0009)\end{array}$ & $\begin{array}{l}0.016^{* *} \\
(0.0009)\end{array}$ & $\begin{array}{l}-0.010 \\
(0.0152)\end{array}$ \\
\hline Specification & (SP1) & (SP2) & (SP3) & (SP4) & (SP5) \\
\hline Year dummies & & yes & yes & & \\
\hline Country effects & & & yes & & \\
\hline Cty-year dummies & & & & yes & yes \\
\hline Region effects & & & & & yes \\
\hline F-statistic & 174.98 & 25.20 & 52.68 & 18.58 & 1236.06 \\
\hline Prob $>F$ & 0.0000 & 0.0000 & 0.0000 & 0.0000 & 0.0000 \\
\hline R-squared & 0.34 & 0.40 & 0.63 & 0.65 & 0.96 \\
\hline $\begin{array}{l}\text { Sum of Coeff. } \\
\text { Linear Homog } \\
\text { (p-value) }\end{array}$ & $\begin{array}{l}-0.00003 \\
(0.9778) \\
\text { Accept }\end{array}$ & $\begin{array}{l}0.0003 \\
(0.8061) \\
\text { Accept }\end{array}$ & $\begin{array}{l}-0.0046 \\
(0.0000) \\
\text { Reject }\end{array}$ & $\begin{array}{l}-0.0046 \\
(0.0000) \\
\text { Reject }\end{array}$ & $\begin{array}{l}-0.1175 \\
(0.0000) \\
\text { Reject }\end{array}$ \\
\hline $\begin{array}{l}\text { Maddala-Wu } \\
\text { (p-value) }\end{array}$ & $\begin{array}{l}\text { (0.500) } \\
\text { Accept }\end{array}$ & $\begin{array}{l}(0.0188) \\
\text { Reject }\end{array}$ & $\begin{array}{l}(0.0389) \\
\text { Reject }\end{array}$ & $\begin{array}{l}\text { (0.0002) } \\
\text { Reject }\end{array}$ & $\begin{array}{l}(0.0000) \\
\text { Reject }\end{array}$ \\
\hline
\end{tabular}

$\overline{\text { Notes: Huber-White heteroscedasticity robust standard errors in parentheses. }{ }^{* *}}$ denotes significance at the $5 \%$ level,

* denotes significance at the $10 \%$ level.

Table 5B: Factor Endowments and Specialization in Manufacturing

\begin{tabular}{|c|c|c|c|c|c|}
\hline$s_{z j t}$ & (1) & (2) & (3) & (4) & (5) \\
\hline Obs & 811 & 811 & 811 & 811 & 811 \\
\hline Years & $1975-95$ & $1975-95$ & $1975-95$ & $1975-95$ & $1975-95$ \\
\hline Capital $_{z t}$ & $\begin{array}{l}0.037^{* *} \\
(0.0039)\end{array}$ & $\begin{array}{l}-0.005 \\
(0.0040)\end{array}$ & $\begin{array}{l}0.071^{* *} \\
(0.0116)\end{array}$ & $\begin{array}{l}0.073^{* *} \\
(0.0130)\end{array}$ & $\begin{array}{l}0.043^{* *} \\
(0.0087)\end{array}$ \\
\hline Population $_{z t}$ & $\begin{array}{l}-0.003 \\
(0.0059)\end{array}$ & $\begin{array}{l}-0.008 \\
(0.0058)\end{array}$ & $\begin{array}{l}-0.079^{* *} \\
(0.0124)\end{array}$ & $\begin{array}{l}-0.081^{* *} \\
(0.0137)\end{array}$ & $\begin{array}{l}0.206^{* *} \\
(0.0295)\end{array}$ \\
\hline $\operatorname{Land}_{z t}$ & $\begin{array}{c}-0.040 * * \\
(0.0024)\end{array}$ & $\begin{array}{l}0.021 * * \\
(0.0023)\end{array}$ & $\begin{array}{l}0.032^{* *} \\
(0.0027)\end{array}$ & $\begin{array}{l}0.032 * * \\
(0.0029)\end{array}$ & $\begin{array}{l}-0.125^{* *} \\
(0.0638)\end{array}$ \\
\hline Specification & (SP1) & (SP2) & (SP3) & (SP4) & (SP5) \\
\hline $\begin{array}{l}\text { Year dummies } \\
\text { Country effects } \\
\text { Cty-year dummies } \\
\text { Region effects }\end{array}$ & & yes & $\begin{array}{l}\text { yes } \\
\text { yes }\end{array}$ & yes & $\begin{array}{l}\text { yes } \\
\text { yes }\end{array}$ \\
\hline F-statistic & 122.09 & 16.94 & 21.27 & 75.34 & 479.64 \\
\hline Prob $>F$ & 0.0000 & 0.0000 & 0.0000 & 0.0000 & 0.0000 \\
\hline R-squared & 0.23 & 0.29 & 0.40 & 0.41 & 0.97 \\
\hline $\begin{array}{l}\text { Sum of Coeff. } \\
\text { Linear Homog } \\
(p \text {-value })\end{array}$ & $\begin{array}{l}0.0066 \\
(0.0694) \\
\text { Accept }\end{array}$ & $\begin{array}{l}0.0082 \\
(0.0133) \\
\text { Reject }\end{array}$ & $\begin{array}{l}0.0239 \\
(0.0000) \\
\text { Reject }\end{array}$ & $\begin{array}{l}0.0240 \\
(0.0000) \\
\text { Reject }\end{array}$ & $\begin{array}{l}0.1239 \\
(0.0652) \\
\text { Accept }\end{array}$ \\
\hline $\begin{array}{l}\text { Maddala-Wu } \\
\text { (p-value) }\end{array}$ & $\begin{array}{l}(0.4964) \\
\text { Accept }\end{array}$ & $\begin{array}{l}(0.0040) \\
\text { Reject }\end{array}$ & $\begin{array}{l}(0.0020) \\
\text { Reject }\end{array}$ & $\begin{array}{l}(0.0404) \\
\text { Reject }\end{array}$ & $\begin{array}{l}\text { (0.1372) } \\
\text { Accept }\end{array}$ \\
\hline
\end{tabular}

Notes: Huber-White heteroscedasticity robust standard errors in parentheses. ${ }^{* *}$ denotes significance at the $5 \%$ level,

* denotes significance at the $10 \%$ level. 
Table 5C: Factor Endowments and Specialization in Services

\begin{tabular}{|c|c|c|c|c|c|}
\hline$s_{z j t}$ & (1) & $(2)$ & $(3)$ & (4) & $(5)$ \\
\hline Obs & 811 & 811 & 811 & 811 & 811 \\
\hline Years & $1975-95$ & $1975-95$ & $1975-95$ & $1975-95$ & $1975-95$ \\
\hline Capital $_{z t}$ & $\begin{array}{l}0.037^{* *} \\
(0.0039)\end{array}$ & $\begin{array}{l}0.0006 \\
(0.0039)\end{array}$ & $\begin{array}{l}-0.049^{* *} \\
(0.0100)\end{array}$ & $\begin{array}{l}-0.054^{* *} \\
(0.0111)\end{array}$ & $\begin{array}{l}-0.053^{* *} \\
(0.0095)\end{array}$ \\
\hline Population $_{z t}$ & $\begin{array}{l}-0.003 \\
(0.0059)\end{array}$ & $\begin{array}{l}0.029^{* *} \\
(0.0057)\end{array}$ & $\begin{array}{l}0.078^{* *} \\
(0.0106)\end{array}$ & $\begin{array}{l}0.083^{* *} \\
(0.0117)\end{array}$ & $\begin{array}{l}-0.089^{* *} \\
(0.0277)\end{array}$ \\
\hline $\operatorname{Land}_{z t}$ & $\begin{array}{l}-0.040^{* *} \\
(0.0024)\end{array}$ & $\begin{array}{l}-0.038^{* *} \\
(0.0021)\end{array}$ & $\begin{array}{c}-0.048^{* *} \\
(0.0025)\end{array}$ & $\begin{array}{l}-0.048^{* *} \\
(0.0027)\end{array}$ & $\begin{array}{l}0.136^{* *} \\
(0.0587)\end{array}$ \\
\hline Specification & (SP1) & (SP2) & (SP3) & (SP4) & (SP5) \\
\hline Year dummies & & yes & yes & & \\
\hline Country effects & & & yes & & \\
\hline Cty-year dummies & & & & yes & yes \\
\hline Region effects & & & & & yes \\
\hline F-statistic & 122.09 & 38.63 & 47.01 & 397.29 & 884.48 \\
\hline Prob $>F$ & 0.0000 & 0.0000 & 0.0000 & 0.0000 & 0.0000 \\
\hline R-squared & 0.2288 & 0.4528 & 0.5298 & 0.5448 & 0.9762 \\
\hline $\begin{array}{l}\text { Sum of Coeff. } \\
\text { Linear Homog } \\
\text { (p-value) }\end{array}$ & $\begin{array}{l}-0.0066 \\
(0.0694) \\
\text { Accept }\end{array}$ & $\begin{array}{l}-0.0085 \\
(0.0091) \\
\text { Reject }\end{array}$ & $\begin{array}{l}-0.0192 \\
(0.0001) \\
\text { Reject }\end{array}$ & $\begin{array}{l}-0.0195 \\
(0.0001) \\
\text { Reject }\end{array}$ & $\begin{array}{l}-0.0064 \\
(0.9187) \\
\text { Accept }\end{array}$ \\
\hline $\begin{array}{l}\text { Maddala-Wu } \\
\text { (p-value) }\end{array}$ & $\begin{array}{l}\text { (0.5000) } \\
\text { Accept }\end{array}$ & $\begin{array}{l}\text { (0.1705) } \\
\text { Accept }\end{array}$ & $\begin{array}{l}\text { (0.2460) } \\
\text { Accept }\end{array}$ & $\begin{array}{l}\text { (0.0679) } \\
\text { Accept }\end{array}$ & $\begin{array}{l}(0.0303) \\
\text { Reject }\end{array}$ \\
\hline
\end{tabular}

Notes: Huber-White heteroscedasticity robust standard errors in parentheses. ${ }^{* *}$ denotes significance at the $5 \%$ level,

* denotes significance at the $10 \%$ level.

Table 6: Factor Endowments and Specialization at the Aggregate Level

\begin{tabular}{|c|c|c|c|c|c|c|}
\hline$s_{z j t}$ & (1) & $(2)$ & $(3)$ & (4) & (5) & $(6)$ \\
\hline Obs & 696 & 696 & 696 & 696 & 696 & 696 \\
\hline Years & $1975-95$ & $1975-95$ & $1975-95$ & 1975-95 & $1975-95$ & $1975-95$ \\
\hline Capital $_{z t}$ & $\begin{array}{l}-0.015^{* *} \\
(0.0036)\end{array}$ & $\begin{array}{l}0.082^{* *} \\
(0.0138)\end{array}$ & $\begin{array}{l}-0.066^{* *} \\
(0.0126)\end{array}$ & $\begin{array}{l}0.010^{* *} \\
(0.0048)\end{array}$ & $\begin{array}{l}0.063^{* *} \\
(0.0117)\end{array}$ & $\begin{array}{l}-0.073^{* *} \\
(0.0115)\end{array}$ \\
\hline Low $\operatorname{Educ}_{z t}$ & $\begin{array}{l}0.026^{* *} \\
(0.0046)\end{array}$ & $\begin{array}{l}-0.030^{*} \\
(0.0169)\end{array}$ & $\begin{array}{l}0.004 \\
(0.0153)\end{array}$ & $\begin{array}{l}-0.019^{* *} \\
(0.0042)\end{array}$ & $\begin{array}{l}0.0005 \\
(0.0111)\end{array}$ & $\begin{array}{l}0.018^{*} \\
(0.0104)\end{array}$ \\
\hline Med $\operatorname{Educ}_{z t}$ & $\begin{array}{l}-0.029 * * \\
(0.0044)\end{array}$ & $\begin{array}{l}0.069^{* *} \\
(0.0172)\end{array}$ & $\begin{array}{l}-0.040^{* *} \\
(0.0168)\end{array}$ & $\begin{array}{l}-0.012^{* *} \\
(0.0026)\end{array}$ & $\begin{array}{l}0.023^{* *} \\
(0.0066)\end{array}$ & $\begin{array}{l}-0.011^{* *} \\
(0.0057)\end{array}$ \\
\hline High $\operatorname{Educ}_{z t}$ & $\begin{array}{l}-0.001 \\
(0.0033)\end{array}$ & $\begin{array}{l}-0.125^{* *} \\
(0.0148)\end{array}$ & $\begin{array}{l}0.126^{* *} \\
(0.0141)\end{array}$ & $\begin{array}{l}-0.007 * * \\
(0.0022)\end{array}$ & $\begin{array}{l}0.004 \\
(0.0052)\end{array}$ & $\begin{array}{l}0.003 \\
(0.0050)\end{array}$ \\
\hline Arable land $z t$ & $\begin{array}{l}0.012^{* *} \\
(0.0008)\end{array}$ & $\begin{array}{l}0.020 * * \\
(0.0025)\end{array}$ & $\begin{array}{c}-0.032^{* *} \\
(0.0022)\end{array}$ & $\begin{array}{l}-0.0004 \\
(0.0030)\end{array}$ & $\begin{array}{l}0.015 \\
(0.0126)\end{array}$ & $\begin{array}{c}-0.015^{* *} \\
(0.0141)\end{array}$ \\
\hline $\begin{array}{l}\text { Industry } \\
\text { Specification }\end{array}$ & $\begin{array}{l}\text { Agric } \\
\text { (SP4) }\end{array}$ & $\begin{array}{l}\text { Manu } \\
\text { (SP4) }\end{array}$ & $\begin{array}{l}\text { Serv } \\
(\text { SP4) }\end{array}$ & $\begin{array}{l}\text { Agric } \\
\text { (SP5) }\end{array}$ & $\begin{array}{l}\text { Manu } \\
\text { (SP5) }\end{array}$ & $\begin{array}{l}\text { Serv } \\
\text { (SP5) }\end{array}$ \\
\hline Regional effects & & & & yes & yes & yes \\
\hline Cty-year dummies & yes & yes & yes & yes & yes & yes \\
\hline F-statistic & 179.91 & 7.65 & 19.44 & 165.14 & 452.03 & 443.84 \\
\hline Prob $>F$ & 0.0000 & 0.0000 & 0.0000 & 0.0000 & 0.0000 & 0.0000 \\
\hline R-squared & 0.67 & 0.50 & 0.61 & 0.96 & 0.97 & 0.97 \\
\hline $\begin{array}{l}\text { Sum of Coeff. } \\
\text { Linear Homog } \\
\text { (p-value) } \\
\text { Maddala-Wu } \\
\text { (p-value) }\end{array}$ & $\begin{array}{l}-0.0068 \\
(0.0000) \\
\text { Reject } \\
(0.0000) \\
\text { Reject }\end{array}$ & $\begin{array}{l}0.0155 \\
(0.0080) \\
\text { Reject } \\
(0.0000) \\
\text { Reject }\end{array}$ & $\begin{array}{l}-0.0087 \\
(0.1203) \\
\text { Accept } \\
(0.0037) \\
\text { Reject }\end{array}$ & $\begin{array}{l}-0.0281 \\
(0.0000) \\
\text { Reject } \\
(0.0315) \\
\text { Reject }\end{array}$ & $\begin{array}{l}0.1056 \\
(0.0000) \\
\text { Reject } \\
(0.0005) \\
\text { Reject }\end{array}$ & $\begin{array}{l}-0.0775 \\
(0.0035) \\
\text { Reject } \\
(0.0154) \\
\text { Reject }\end{array}$ \\
\hline
\end{tabular}

Notes: Huber-White heteroscedasticity robust standard errors in parentheses. ${ }^{* *}$ denotes significance at the $5 \%$ level,

* denotes significance at the $10 \%$ level. 
Table 7: Factor Endowments and Specialization at the Aggregate Level (Long Differences)

\begin{tabular}{|c|c|c|c|}
\hline$\triangle s_{z j t}$ & (1) & $(2)$ & $(3)$ \\
\hline Obs & 341 & 341 & 341 \\
\hline Years & $1975-95$ & $1975-95$ & 1975-95 \\
\hline$\triangle$ Capital $_{z t}$ & $\begin{array}{l}-0.006 \\
(0.0043)\end{array}$ & $\begin{array}{l}0.062^{* *} \\
(0.0104)\end{array}$ & $\begin{array}{l}-0.057^{* *} \\
(0.0112)\end{array}$ \\
\hline$\triangle$ Low $\operatorname{Educ}_{z t}$ & $\begin{array}{l}-0.035^{* *} \\
(0.0043)\end{array}$ & $\begin{array}{l}-0.009 \\
(0.0185)\end{array}$ & $\begin{array}{l}0.044^{* *} \\
(0.0187)\end{array}$ \\
\hline$\triangle \operatorname{Med} \operatorname{Educ}_{z t}$ & $\begin{array}{r}-0.031^{* *} \\
(0.0038)\end{array}$ & $\begin{array}{l}0.023^{* *} \\
(0.0082)\end{array}$ & $\begin{array}{l}0.008 \\
(0.0081)\end{array}$ \\
\hline$\triangle \operatorname{High} \operatorname{Educ}_{z t}$ & $\begin{array}{l}-0.010^{* *} \\
(0.0017)\end{array}$ & $\begin{array}{l}-0.002 \\
(0.0042)\end{array}$ & $\begin{array}{l}0.012^{* *} \\
(0.0044)\end{array}$ \\
\hline$\triangle$ Arable Land $z t$ & $\begin{array}{l}0.013^{* *} \\
(0.0035)\end{array}$ & $\begin{array}{l}0.018^{*} \\
(0.0108)\end{array}$ & $\begin{array}{c}-0.031^{* *} \\
(0.0122)\end{array}$ \\
\hline Industry & Agric & Manu & Serv \\
\hline Year dummies & yes & yes & yes \\
\hline Difference period & 10 years & 10 years & 10 years \\
\hline F-statistic & 18.42 & 8.57 & 6.58 \\
\hline Prob $>F$ & 0.0000 & 0.0000 & 0.0000 \\
\hline R-squared & 0.46 & 0.21 & 0.19 \\
\hline $\begin{array}{l}\text { Sum of Coeff. } \\
\text { Linear Homog } \\
\text { (p-value) }\end{array}$ & $\begin{array}{l}-0.0685 \\
(0.0000) \\
\text { Reject }\end{array}$ & $\begin{array}{l}0.0915 \\
(0.0016) \\
\text { Reject }\end{array}$ & $\begin{array}{l}-0.0229 \\
(0.4466) \\
\text { Accept }\end{array}$ \\
\hline
\end{tabular}

$\overline{\overline{\text { Notes: Huber-White heteroscedasticity robust standard }}}$ errors in parentheses. ${ }^{* *}$ denotes significance at the $5 \%$ level,

* denotes significance at the $10 \%$ level. 
Table 8: The Quantitative Importance of Factor Endowments, Average Within-sample Prediction Errors ${ }^{(a)}$

\begin{tabular}{|c|c|c|c|c|}
\hline & & (1) & $(2)$ & $(3)$ \\
\hline \multirow[t]{3}{*}{ All countries ${ }^{(b)}$} & $s_{z j t}$ & 0.042 & 0.354 & 0.604 \\
\hline & $\left|s_{z j t}-\hat{s}_{z j t}^{1}\right| / s_{z j t}$ & 0.582 & 0.134 & 0.069 \\
\hline & $s_{z j t}-\hat{s}_{z j t}^{2} \mid / s_{z j t}$ & 6.458 & 0.487 & 0.151 \\
\hline \multirow[t]{3}{*}{ Belgium $^{(b)}$} & $s_{z j t}$ & 0.026 & 0.337 & 0.637 \\
\hline & $\left|s_{z j t}-\hat{s}_{z j t}^{1}\right| / s_{z j t}$ & 0.519 & 0.064 & 0.039 \\
\hline & $s_{z j t}-\hat{s}_{z j t}^{2} \mid / s_{z j t}$ & 5.275 & 0.545 & 0.090 \\
\hline \multirow[t]{3}{*}{ Spain } & $s_{z j t}$ & 0.057 & 0.334 & 0.609 \\
\hline & $\left|s_{z j t}-\hat{s}_{z j t}^{1}\right| / s_{z j t}$ & 1.534 & 0.170 & 0.072 \\
\hline & $\left|s_{z j t}-\hat{s}_{z j t}^{2}\right| / s_{z j t}$ & 10.821 & 0.431 & 0.154 \\
\hline \multirow[t]{3}{*}{ France } & $s_{z j t}$ & 0.043 & 0.337 & 0.620 \\
\hline & $\left|s_{z j t}-\hat{s}_{z j t}^{1}\right| / s_{z j t}$ & 0.677 & 0.117 & 0.046 \\
\hline & $\left|s_{z j t}-\hat{s}_{z j t}^{2}\right| / s_{z j t}$ & 8.857 & 0.518 & 0.118 \\
\hline \multirow[t]{3}{*}{ Italy } & $s_{z j t}$ & 0.048 & 0.339 & 0.613 \\
\hline & $\left|s_{z j t}-\hat{s}_{z j t}^{1}\right| / s_{z j t}$ & 0.281 & 0.122 & 0.054 \\
\hline & $\left|s_{z j t}-\hat{s}_{z j t}^{2}\right| / s_{z j t}$ & 3.038 & 0.501 & 0.145 \\
\hline \multirow[t]{3}{*}{ Luxembourg } & $s_{z j t}$ & 0.024 & 0.342 & 0.634 \\
\hline & $\left|s_{z j t}-\hat{s}_{z j t}^{1}\right| / s_{z j t}$ & $0^{(\mathrm{c})}$ & $0^{(\mathrm{c})}$ & $0^{(c)}$ \\
\hline & $\left|s_{z j t}-\hat{s}_{z j t}^{2}\right| / s_{z j t}$ & 5.084 & 0.864 & 0.280 \\
\hline \multirow[t]{3}{*}{ Netherlands } & $s_{z j t}$ & 0.047 & 0.353 & 0.600 \\
\hline & $\left|s_{z j t}-\hat{s}_{z j t}^{1}\right| / s_{z j t}$ & 0.126 & 0.180 & 0.117 \\
\hline & $s_{z j t}-\hat{s}_{z j t}^{2} \mid / s_{z j t}$ & 3.898 & 0.496 & 0.152 \\
\hline \multirow[t]{6}{*}{ UK } & $s_{z j t}$ & 0.025 & 0.415 & 0.561 \\
\hline & $\left|s_{z j t}-\hat{s}_{z j t}^{1}\right| / s_{z j t}$ & 0.454 & 0.145 & 0.098 \\
\hline & $s_{z j t}-\hat{s}_{z j t}^{2} \mid / s_{z j t}$ & 6.834 & 0.424 & 0.197 \\
\hline & Industry & Agric & Manu & Serv \\
\hline & Specification & (SP4) & (SP4) & (SP4) \\
\hline & Cty-year dummies & yes & yes & yes \\
\hline
\end{tabular}

$\overline{\text { (a) Prediction errors are evaluated using the estimated coefficients }}$ reported in Columns (1)-(3) of Table 6 (SP4). The superscript 1 indicates the use of the regression's fitted values. The superscript 2 indicates the use of predicted values from all right-hand variables except factor endowments.

(b) The reported prediction errors exclude region Be1 (Brussels). Brussels is a capital city, and the share of Agriculture in this region is a clear outlier. As a robustness test, we re-estimated the model excluding this region; this produced very similar estimated coefficients to those reported earlier.

(c) Luxembourg has only one NUTS-1 region. The fitted values for shares of sectors in GDP in the specification with country-year dummies are therefore exactly equal to the actual values (we estimate as many country-year coefficients as there are observations for Luxembourg). We experimented with treating Luxembourg as a region of Belgium; again this yielded very similar estimated coefficients to those reported earlier. 
Table 9: Average Within-sample Predictive Errors over Time ${ }^{(\mathrm{a})}$

\begin{tabular}{|c|c|c|c|c|c|}
\hline & & Period & $(1)$ & $(2)$ & $(3)$ \\
\hline \multirow[t]{3}{*}{ All countries ${ }^{(b)}$} & $\left|s_{z j t}-\hat{s}_{z j t}^{1}\right| / s_{z j t}$ & $1980-85$ & 0.568 & 0.132 & 0.070 \\
\hline & $s_{z j t}-\hat{s}_{z j t}^{1} \mid / s_{z j t}$ & $1985-90$ & 0.735 & 0.130 & 0.062 \\
\hline & $s_{z j t}-\hat{s}_{z j t}^{1} \mid / s_{z j t}$ & 1990-95 & 0.566 & 0.131 & 0.054 \\
\hline \multirow[t]{3}{*}{ Belgium $^{(\mathrm{b})}$} & \begin{tabular}{|l|l|}
$s_{z j t}-\hat{s}_{z j t}^{1}$ & $/ s_{z j t}$
\end{tabular} & $1980-85$ & 0.364 & 0.038 & 0.029 \\
\hline & $s_{z j t}-\hat{s}_{z j t}^{1} \mid / s_{z j t}$ & $1985-90$ & 0.462 & 0.068 & 0.040 \\
\hline & $s_{z j t}-\hat{s}_{z j t}^{1} \mid / s_{z j t}$ & 1990-95 & 0.754 & 0.078 & 0.047 \\
\hline \multirow[t]{3}{*}{ Spain } & \begin{tabular}{|l|l|}
$s_{z j t}-\hat{s}_{z j t}^{1}$ & $/ s_{z j t}$ \\
\end{tabular} & $1980-85$ & 1.221 & 0.192 & 0.083 \\
\hline & $\left|s_{z j t}-\hat{s}_{z j t}^{1}\right| / s_{z j t}$ & $1985-90$ & 1.952 & 0.158 & 0.067 \\
\hline & $s_{z j t}-\hat{s}_{z j t}^{1} \mid / s_{z j t}$ & 1990-95 & 1.513 & 0.164 & 0.064 \\
\hline \multirow[t]{3}{*}{ France } & \begin{tabular}{|l|l|}
$s_{z j t}-\hat{s}_{z j t}^{1}$ & $/ s_{z j t}$
\end{tabular} & $1980-85$ & 0.725 & 0.110 & 0.042 \\
\hline & $\left|s_{z j t}-\hat{s}_{z j t}^{1}\right| / s_{z j t}$ & $1985-90$ & 0.725 & 0.125 & 0.042 \\
\hline & $s_{z j t}-\hat{s}_{z j t}^{1} \mid / s_{z j t}$ & 1990-94 & 0.565 & 0.117 & 0.043 \\
\hline \multirow[t]{3}{*}{ Italy } & \begin{tabular}{|l|l|}
$s_{z j t}-\hat{s}_{z j t}^{1}$ & $/ s_{z j t}$ \\
\end{tabular} & $1980-85$ & 0.341 & 0.108 & 0.048 \\
\hline & $\left|s_{z j t}-\hat{s}_{z j t}^{1}\right| / s_{z j t}$ & $1985-90$ & 0.284 & 0.126 & 0.059 \\
\hline & $\left|s_{z j t}-\hat{s}_{z j t}^{1}\right| / s_{z j t}$ & $1990-95$ & 0.215 & 0.131 & 0.054 \\
\hline \multirow[t]{2}{*}{ Luxembourg } & \begin{tabular}{|l|l}
$s_{z j t}-\hat{s}_{z j t}^{1} \mid$ & $/ s_{z j t}$
\end{tabular} & $1980-85$ & $0^{(\mathrm{c})}$ & $0^{(\mathrm{c})}$ & $0^{(\mathrm{c})}$ \\
\hline & $\left|s_{z j t}-\hat{s}_{z j t}^{1}\right| / s_{z j t}$ & 1985-90 & $0^{(\mathrm{c})}$ & $0^{(\mathrm{c})}$ & $0^{(\mathrm{c})}$ \\
\hline \multirow[t]{3}{*}{ Netherlands } & $\left|s_{z j t}-\hat{s}_{z j t}^{1}\right| / s_{z j t}$ & $1980-85$ & 0.178 & 0.225 & 0.171 \\
\hline & $s_{z j t}-\hat{s}_{z j t}^{1} \mid / s_{z j t}$ & $1985-90$ & 0.105 & 0.170 & 0.104 \\
\hline & $\left|s_{z j t}-\hat{s}_{z j t}^{1}\right| / s_{z j t}$ & 1990-95 & 0.085 & 0.140 & 0.067 \\
\hline \multirow[t]{5}{*}{ UK } & \begin{tabular}{|l|l|}
$s_{z j t}-\hat{s}_{z j t}^{1}$ & $/ s_{z j t}$ \\
\end{tabular} & $1975-80$ & 0.328 & 0.165 & 0.117 \\
\hline & $\left|s_{z j t}-\hat{s}_{z j t}^{1}\right| / s_{z j t}$ & $1980-85$ & 0.495 & 0.129 & 0.082 \\
\hline & Industry & & Agric & Manu & Serv \\
\hline & Specification & & (SP4) & $(\mathrm{SP} 4)$ & (SP4) \\
\hline & Cty-year dummies & & yes & yes & yes \\
\hline
\end{tabular}

$\overline{\text { (a) Prediction errors are evaluated using the estimated coefficients reported }}$ in Columns (1)-(3) of Table 6 (SP4). The superscript 1 indicates the use of the regression's fitted values.

(b) The reported prediction errors exclude region Be1 (Brussels). Brussels is a capital city, and the share of Agriculture in this region is a clear outlier. As a robustness test, we re-estimated the model excluding this region; this produced very similar estimated coefficients to those reported earlier.

(c) Luxembourg has only one NUTS-1 region. The fitted values for shares of sectors in GDP in the specification with country-year dummies are therefore exactly equal to the actual values (we estimate as many country-year coefficients as there are observations for Luxembourg). We experimented with treating Luxembourg as a region of Belgium; again this yielded very similar estimated coefficients to those reported earlier. 
Table 10A: Average Within-sample Prediction Errors in the Disaggregated Manufacturing Industries over Time $^{(a)}$

\begin{tabular}{|c|c|c|c|c|c|c|c|}
\hline & Period & $(1)$ & $(2)$ & $(3)$ & $(4)$ & $(5)$ & (6) \\
\hline \multirow[t]{3}{*}{ All countries ${ }^{(b),(c)}$} & $1980-85$ & 0.570 & 2.129 & 0.270 & 0.444 & 0.443 & 0.575 \\
\hline & $1985-90$ & 0.554 & 1.397 & 0.283 & 0.336 & 0.459 & 0.493 \\
\hline & $1990-95$ & 0.542 & 1.239 & 0.287 & 0.387 & 0.495 & 0.520 \\
\hline \multirow[t]{3}{*}{ Belgium $^{(b)}$} & $1980-85$ & 0.306 & 0.332 & 0.561 & 0.252 & 0.253 & 1.055 \\
\hline & $1985-90$ & 0.271 & 0.192 & 0.484 & 0.213 & 0.066 & 0.132 \\
\hline & $1990-95$ & 0.349 & 0.200 & 0.400 & 0.209 & 0.076 & 0.139 \\
\hline \multirow[t]{3}{*}{ Spain $^{(c)}$} & $1980-85$ & 0.521 & 1.856 & 0.221 & 0.741 & 0.989 & 1.295 \\
\hline & $1985-90$ & 0.353 & 2.460 & 0.299 & 0.497 & 1.037 & 0.681 \\
\hline & 1990-94 & 0.311 & 1.983 & 0.293 & 0.548 & 1.060 & 0.842 \\
\hline \multirow[t]{3}{*}{ France } & $1980-85$ & 0.328 & 0.934 & 0.204 & 0.318 & 0.276 & 0.285 \\
\hline & $1985-90$ & 0.360 & 1.051 & 0.245 & 0.339 & 0.252 & 0.367 \\
\hline & 1990-94 & 0.454 & 1.438 & 0.220 & 0.342 & 0.281 & 0.348 \\
\hline \multirow[t]{3}{*}{ Italy } & $1980-85$ & 0.390 & 1.298 & 0.306 & 0.330 & 0.492 & 0.582 \\
\hline & $1985-90$ & 0.393 & 1.194 & 0.281 & 0.307 & 0.453 & 0.680 \\
\hline & 1990-95 & 0.346 & 1.213 & 0.283 & 0.435 & 0.448 & 0.592 \\
\hline \multirow[t]{2}{*}{ Luxembourg } & $1980-85$ & $0^{(d)}$ & $0^{(d)}$ & $0^{(d)}$ & $0^{(d)}$ & $0^{(d)}$ & $0^{(d)}$ \\
\hline & $1985-90$ & $0^{(\mathrm{d})}$ & $0^{(\mathrm{d})}$ & $0^{(\mathrm{d})}$ & $0^{(\mathrm{d})}$ & $0^{(\mathrm{d})}$ & $0^{(\mathrm{d})}$ \\
\hline \multirow[t]{3}{*}{ Netherlands } & $1980-85$ & 1.576 & 1.097 & 0.353 & 0.330 & 0.379 & 0.322 \\
\hline & $1985-90$ & 1.708 & 0.639 & 0.351 & 0.213 & 0.398 & 0.364 \\
\hline & $1990-95$ & 1.683 & 0.624 & 0.357 & 0.198 & 0.385 & 0.347 \\
\hline \multirow[t]{4}{*}{ UK } & $1975-80$ & 0.620 & 3.139 & 0.472 & 0.548 & 0.328 & 0.502 \\
\hline & $1980-85$ & 0.689 & 4.875 & 0.253 & 0.579 & 0.268 & 0.378 \\
\hline & $\begin{array}{l}\text { Industry } \\
\text { Specification }\end{array}$ & $\begin{array}{l}\text { Fuel } \\
\text { (SP4) }\end{array}$ & $\begin{array}{l}\text { Ferrous } \\
\text { (SP4) }\end{array}$ & $\begin{array}{l}\text { Minerals } \\
\text { (SP4) }\end{array}$ & $\begin{array}{l}\text { Chemical } \\
\text { (SP4) }\end{array}$ & $\begin{array}{l}\text { Machine } \\
\text { (SP4) }\end{array}$ & $\begin{array}{l}\text { Transport } \\
\text { (SP4) }\end{array}$ \\
\hline & Cty-year dummies & yes & yes & yes & yes & yes & yes \\
\hline
\end{tabular}

$\overline{\text { (a) Prediction errors are }\left|s_{z j t}-\hat{s}_{z j t}\right| / s_{z j t} \text {, and are evaluated using the fitted values from the regressions }}$ reported in Table $\mathrm{C} 1$ in Appendix C (SP4).

(b) The reported prediction errors exclude region Be1 (Brussels). Brussels is a capital city, and the shares of some disaggregated manufacturing industries in this region are clear outliers. As a robustness test, we reestimated the model excluding this region; this produced very similar estimated coefficients to those reported earlier.

(c) The reported prediction errors exclude the Metal industry in region Esp7 (Canaries). From Table 2, Metal constitutes a very small share of GDP in this region. As a robustness test, we re-estimated the model excluding this region; this produced very similar estimated coefficients to those reported earlier.

(d) Luxembourg has only one NUTS-1 region. The fitted values for shares of sectors in GDP in the specification with country-year dummies are therefore exactly equal to the actual values (we estimate as many country-year coefficients as there are observations for Luxembourg). We experimented with treating Luxembourg as a region of Belgium; again this yielded very similar estimated coefficients to those reported earlier. 
Table 10B: Average Within-sample Prediction Errors in the Disaggregated Manufacturing Industries over Time $^{(\mathrm{a})}$

\begin{tabular}{lllllll}
\hline \hline & Period & $(1)$ & $(2)$ & $(3)$ & $(4)$ & $(5)$ \\
\hline All countries & $1980-85$ & 0.243 & 0.824 & 0.242 & 0.307 & 0.123 \\
& $1985-90$ & 0.242 & 0.715 & 0.329 & 0.310 & 0.113 \\
& $1990-95$ & 0.253 & 0.789 & 0.367 & 0.348 & 0.086 \\
\hline Belgium $^{(b)}$ & $1980-85$ & 0.293 & 0.183 & 0.219 & 0.414 & 0.027 \\
& $1985-90$ & 0.223 & 0.243 & 0.178 & 0.172 & 0.055 \\
& $1990-95$ & 0.300 & 0.199 & 0.162 & 0.159 & 0.033 \\
\hline Spain & $1980-85$ & 0.137 & 1.491 & 0.316 & 0.391 & 0.100 \\
& $1985-90$ & 0.150 & 0.848 & 0.409 & 0.493 & 0.110 \\
& $1990-95$ & 0.152 & 0.968 & 0.418 & 0.484 & 0.097 \\
\hline France & $1980-85$ & 0.177 & 0.437 & 0.201 & 0.247 & 0.095 \\
& $1985-90$ & 0.163 & 0.459 & 0.199 & 0.292 & 0.077 \\
& $1990-94$ & 0.188 & 0.455 & 0.223 & 0.353 & 0.078 \\
\hline Italy & $1980-85$ & 0.261 & 0.619 & 0.383 & 0.292 & 0.182 \\
& $1985-90$ & 0.286 & 0.790 & 0.564 & 0.274 & 0.152 \\
& $1990-95$ & 0.355 & 1.040 & 0.551 & 0.343 & 0.089 \\
\hline Luxembourg & $1980-85$ & $0^{(c)}$ & $0^{(c)}$ & $0^{(c)}$ & $0^{(c)}$ & $0^{(c)}$ \\
& $1985-90$ & $0^{(c)}$ & $0^{(c)}$ & $0^{(c)}$ & $0^{(c)}$ & $0^{(c)}$ \\
\hline \hline Netherlands & $1980-85$ & 0.166 & 1.634 & 0.111 & 0.371 & 0.078 \\
& $1985-90$ & 0.278 & 1.159 & 0.134 & 0.276 & 0.100 \\
& $1990-95$ & 0.215 & 0.723 & 0.144 & 0.261 & 0.108 \\
\hline UK & $1975-80$ & 0.399 & 1.128 & 0.265 & 0.330 & 0.095 \\
& $1980-85$ & 0.382 & 0.782 & 0.159 & 0.296 & 0.142 \\
\hline Industry & Food & Textile & Paper & Other & Construction \\
& Specification & $\mathbf{( S P 4 )}$ & $\mathbf{( S P 4 )}$ & $\mathbf{( S P 4 )}$ & $\mathbf{( S P 4 )}$ & (SP4) \\
\hline
\end{tabular}

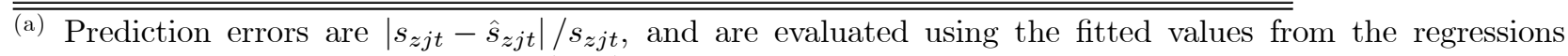
reported in Table $\mathrm{C} 1$ in Appendix C (SP4).

(b) The reported prediction errors exclude region Be1 (Brussels). Brussels is a capital city, and the shares of some disaggregated manufacturing industries in this region are clear outliers. As a robustness test, we reestimated the model excluding this region; this produced very similar estimated coefficients to those reported earlier.

(c) Luxembourg has only one NUTS-1 region. The fitted values for shares of sectors in GDP in the specification with country-year dummies are therefore exactly equal to the actual values (we estimate as many country-year coefficients as there are observations for Luxembourg). We experimented with treating Luxembourg as a region of Belgium; again this yielded very similar estimated coefficients to those reported earlier. 


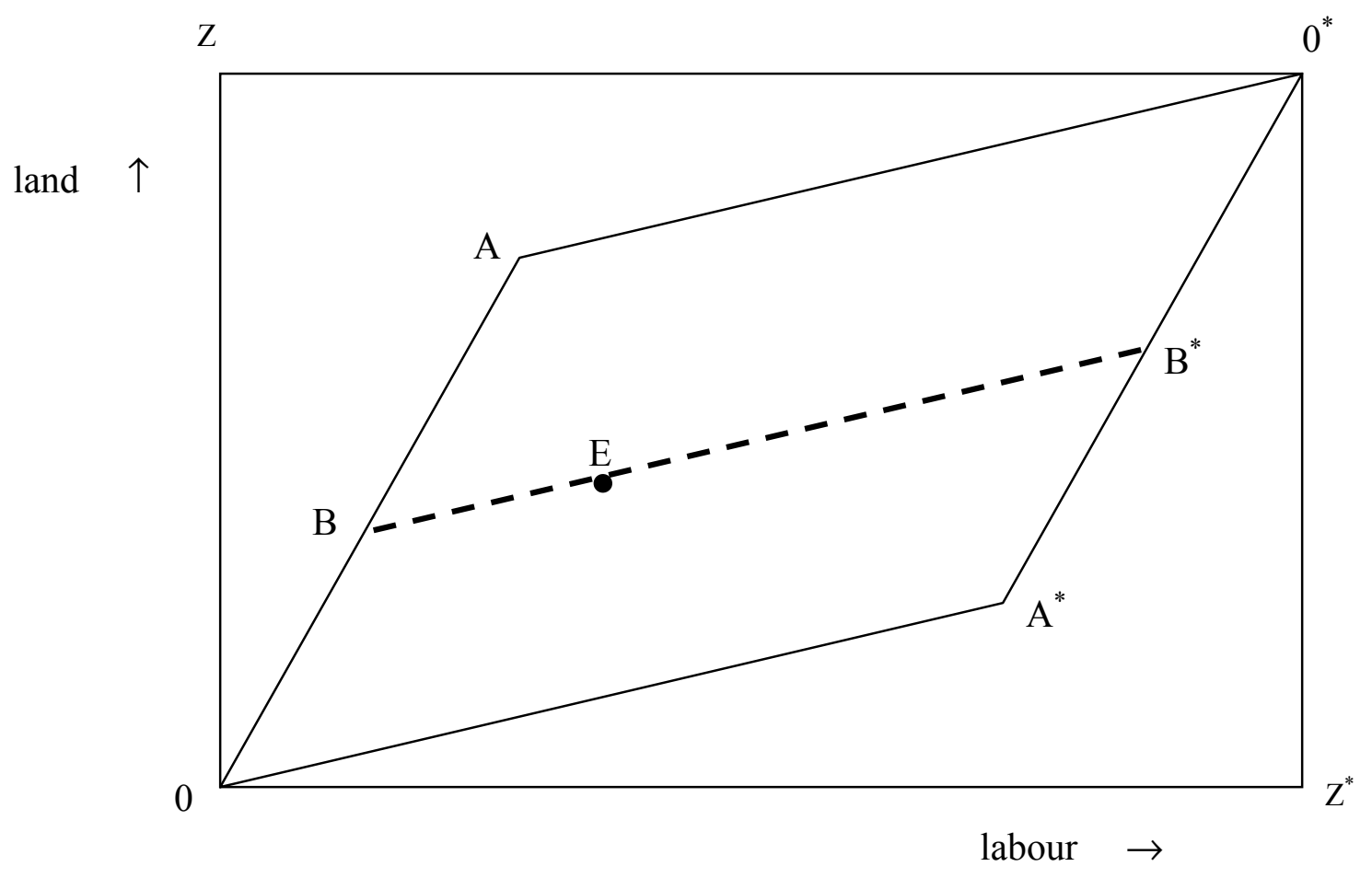

Figure 1: Integrated Equilibrium and Regional Factor Endowments 


\section{Appendix A}

Table A1: Sample Composition

\begin{tabular}{llll}
\hline \hline Country & Sample A & Sample B & Number of NUTS1 regions \\
\hline Belgium & $1975-95$ & $1979-95$ & 3 (be1-be3) \\
Spain & $1980-95$ & $1980-94$ & 7 (esp1- esp7) \\
France & $1975-95$ & $1977-94$ & 8 (fra1-fra8) \\
Italy & $1975-95$ & $1980-95$ & $11($ ita1-ita9, itaa/b) \\
Luxembourg & $1975-95$ & $1979-90$ & $1($ lux $)$ \\
Netherlands & $1975-95$ & $1977-95$ & $4($ ndl1-ndl4) \\
United Kingdom & $1975-86$ & $1975-86$ & $11($ uk1-uk9, uka/b) \\
\hline \hline
\end{tabular}

Table A2: Industry Composition

\begin{tabular}{ll}
\hline \hline Code & Industry Description \\
\hline 1 & Agricultural Sector: Food, Forestry and Fishery Products (Agric) \\
2 & Manufacturing Sector (Manu) \\
3 & Services Sector: Market Services (Serv) \\
4 & Fuel And Power Products (Fuel) \\
5 & Ferrous And Non-Ferrous Ores And Metals, Other Than Radioactive (Metal) \\
6 & Non-Metallic Minerals And Mineral Products (Mineral) \\
7 & Chemical Products (Chem) \\
8 & Metal Products, Machinery, Equipment And Electrical Goods (Machine) \\
9 & Transport Equipment (Transp) \\
11 & Food, Beverages And Tobacco (Food) \\
12 & Textiles And Clothing, Leather And Footwear (Textile) \\
13 & Paper And Printing Products (Paper) \\
14 & Products Of Various Industries (Other) \\
15 & Building And Construction (Constr) \\
\hline \hline
\end{tabular}


Table A3: Regions Included in the Sample

\begin{tabular}{ll}
\hline \hline Code & Description \\
\hline BE1 & Brussels \\
BE2 & Vlaams Gewest \\
BE3 & Region Wallonne \\
ESP1 & North West (E) \\
ESP2 & North East (E) \\
ESP3 & Madrid \\
ESP4 & Centre (E) \\
ESP5 & East (E) \\
ESP6 & South (E) \\
ESP7 & Canaries \\
FR1 & Ile De France \\
FR2 & Bassin Parisien \\
FR3 & Nord-Pas-de-Calais \\
FR4 & East (F) \\
FR5 & West (F) \\
FR6 & South West (F) \\
FR7 & Centre-East (F) \\
FR8 & Mediterranean \\
IT1 & North West (I) \\
IT2 & Lombardia \\
IT3 & Nord East (I) \\
IT4 & Emilia-Romagna \\
IT5 & Centre (I) \\
IT6 & Lazio \\
IT7 & Abruzzo-Molise \\
IT8 & Campania \\
IT9 & South (I) \\
ITA & Sicily \\
ITB & Sardinia \\
LUX & Luxembourg (Grand-Duche) \\
NL1 & North-Netherland \\
NL2 & East-Netherland \\
NL3 & West-Netherland \\
NL4 & South-Netherland \\
UK1 & North (UK) \\
UK2 & Yorkshire And Humberside \\
UK3 & East Midlands \\
UK4 & East Anglia \\
UK5 & South East (UK) \\
UK6 & South West (UK) \\
UK7 & West Midlands \\
UK8 & North West (UK) \\
UK9 & Scotland \\
\hline \hline & Northern Ireland \\
\hline
\end{tabular}




\section{Appendix B}

\section{B1. Regional-level Data on Production and Endowments}

1. Value Added: current price value-added, millions of ECUs, from Regio dataset, Eurostat.

2. GDP: current price, millions of ECUs, from Regio dataset, Eurostat.

3. Population: total population, thousands of people, from Regio dataset, Eurostat.

4. Land: total land area, thousands of hectares, from Regio dataset, Eurostat.

5. Arable Land: total arable land area, thousands of hectares, from Regio dataset, Eurostat.

6. Capital Stock: constructed by the perpetual inventory method (see, for example, Barro and Sala-i-Martin (1995)) using regional-level data on investment (Gross Fixed Capital Formation), constant 1990 prices, millions of ECUs. The main source for the investment data is the Regio dataset, Eurostat. Current price investment was converted into constant prices using price deflators from the Penn World Tables, 5.6. For some countries, regional current price investment data were extended backwards in time using country-level information from the IMF International Financial Statistics (IFS).

\section{B2. Summary of Educational Attainment Data Sources}

Following the labour market literature (see, for example, Nickell and Bell (1996) and Machin and Van Reenen (1998)), educational attainment is grouped into three categories: low, medium and high. 'Low education' is no or primary education, while 'high education' is College degree or equivalent. 'Medium education' corresponds to all intermediate levels of educational attainment, including secondary school and vocational qualifications. Using individual country labour force surveys, we compute the percentage of the population with each level of educational attainment. The endowment variables included in the regressions are these percentages multiplied by the population data from Regio, Eurostat.

1. Belgium: regional data on educational attainment from Annuaire de Statistiques Regionales. Years available are 1970, 1977, 1981 and 1991. Linear interpolation of the data.

2. Spain: educational attainment data from Spanish Labour Force, Instituto Nacional de Estadistica. Years available are 1977, 1979, 1981, and 1983-94. Linear interpolation of the data when required.

3. Italy: educational attainment data from 1986-97 is from Forze di Lavoro and Rilevazione delle forze di Lavore, ISTAT. For years prior to 1986, the regional data is extended backwards in time using country-level information from Nickell et al. (2000).

4. France: educational attainment data from Key data on Education, DG for Education and Culture, European Commission. Years available are 1993 and 1995. Linear interpolation of the data for 1994. The regional data are extended backwards in time country-level information from Nickell et al. (2000).

5. Netherlands: Data from National Statistical Office, years 1992-98. The regional data are extended backwards in time using country-level information from Nickell et al. (2000).

6. Luxembourg: Data are from Belgian region closest to Luxembourg (be3, Region Wallone). 
7. United Kingdom: Data from the Labour Force Survey, years 1977, 1979, 1981, and 1983-94. Linear interpolation of the data when required. Bibliographic citation: Office for National Statistics Labour Market Statistics Group, Department of Finance and Personnel (Northern Ireland), Central Survey Unit, Quarterly Labour Force Survey. Data distributed by the Data Archive, Colchester, Essex. Data disclaimer: although all efforts are made to ensure the quality of the materials, neither the copyright holder, the original data producer, the relevant funding agency, The Data Archive, bear any responsibility for the accuracy or comprehensiveness of these materials. 


\section{Appendix C}

Table C1A: Factor Endowments and Specialisation at the Disaggregate Level

\begin{tabular}{lllllll}
\hline \hline$s_{z j t}$ & $(1)$ & $(2)$ & $(3)$ & $(4)$ & $(5)$ & $(6)$ \\
Obs & 696 & 689 & 689 & 696 & 696 & 693 \\
Years & $1975-95$ & $1975-95$ & $1975-95$ & $1975-95$ & $1975-95$ & $1975-95$ \\
\hline Capital $_{z t}$ & $-0.014^{*}$ & $-0.014^{* *}$ & $-0.003^{* *}$ & $0.007^{* *}$ & $0.056^{* *}$ & $0.004^{*}$ \\
& $(0.0080)$ & $(0.0024)$ & $(0.0011)$ & $(0.0017)$ & $(0.0056)$ & $(0.0025)$ \\
Low Educ $_{z t}$ & -0.003 & $0.011^{* *}$ & $0.003^{* *}$ & 0.003 & $-0.048^{* *}$ & $-0.007^{* *}$ \\
& $(0.0101)$ & $(0.0033)$ & $(0.0013)$ & $(0.0021)$ & $(0.0079)$ & $(0.0028)$ \\
Med Educ $_{z t}$ & -0.008 & $0.016^{* *}$ & $0.004^{* *}$ & -0.001 & $0.044^{* *}$ & $0.020^{* *}$ \\
& $\left(0.010^{*}\right)$ & $(0.0040)$ & $(0.0014)$ & $(0.0030)$ & $(0.0107)$ & $(0.0040)$ \\
High Educ $_{z t}$ & -0.002 & $-0.011^{* *}$ & $-0.007^{* *}$ & -0.001 & $-0.038^{* *}$ & $-0.011^{* *}$ \\
& $(0.0069)$ & $(0.0024)$ & $(0.0011)$ & $(0.0021)$ & $(0.0062)$ & $(0.0029)$ \\
Arable Land $z t$ & $0.007^{* *}$ & 0.0002 & $0.002^{* *}$ & -0.0004 & $0.0019^{* *}$ & -0.0004 \\
& $(0.0015)$ & $(0.0005)$ & $(0.0002)$ & $(0.0004)$ & $(0.0010)$ & $(0.0004)$ \\
\hline Industry & Fuel & Metal & Mineral & Chem & Machine & Transp \\
Specification & $(\mathbf{S P 4})$ & $(\mathbf{S P 4})$ & $(\mathbf{S P 4})$ & $(\mathbf{S P 4})$ & $(\mathbf{S P 4})$ & $(\mathbf{S P 4})$ \\
\hline Cty-year dummies & yes & yes & yes & yes & yes & yes \\
\hline F-statistic & 36.80 & 20092.88 & 16910.22 & 6.69 & 5.60 & 3.94 \\
Prob>F & 0.0000 & 0.0000 & 0.0000 & 0.0000 & 0.0000 & 0.0000 \\
R-squared & 0.27 & 0.67 & 0.50 & 0.32 & 0.38 & 0.36 \\
\hline Sum of Coeff. & -0.0191 & 0.0020 & -0.0011 & 0.0067 & 0.0157 & 0.0059 \\
Linear Homog & $(0.0000)$ & $(0.0092)$ & $(0.0055)$ & $(0.0000)$ & $(0.0000)$ & $(0.0000)$ \\
$(p$-value) & Reject & Reject & Reject & Reject & Reject & Reject \\
Maddala-Wu & $(0.0134)$ & $(0.0032)$ & $(0.0000)$ & $(0.0322)$ & $(0.0443)$ & $(0.0026)$ \\
(p-value) & Reject & Reject & Reject & Reject & Reject & Reject \\
\hline \hline
\end{tabular}

Table C1B: Factor Endowments and Specialisation at the Disaggregate Level

\begin{tabular}{|c|c|c|c|c|c|}
\hline$s_{z j t}$ & (1) & $(2)$ & $(3)$ & $(4)$ & $(5)$ \\
\hline Obs & 696 & 696 & 696 & 696 & 696 \\
\hline Years & 1975-95 & $1975-95$ & $1975-95$ & $1975-95$ & $1975-95$ \\
\hline Capital $_{z t}$ & $\begin{array}{l}0.012^{* *} \\
(0.0029)\end{array}$ & $\begin{array}{l}0.022^{* *} \\
(0.0030)\end{array}$ & $\begin{array}{l}0.014^{* *} \\
(0.0009)\end{array}$ & $\begin{array}{l}0.020^{* *} \\
(0.0016)\end{array}$ & $\begin{array}{l}-0.022^{* *} \\
(0.0023)\end{array}$ \\
\hline Low $\operatorname{Educ}_{z t}$ & $\begin{array}{l}0.011^{* *} \\
(0.0049)\end{array}$ & $\begin{array}{l}0.003 \\
(0.0037)\end{array}$ & $\begin{array}{l}-0.017^{* *} \\
(0.0013)\end{array}$ & $\begin{array}{l}-0.012^{* *} \\
(0.0021)\end{array}$ & $\begin{array}{l}0.027^{* *} \\
(0.0032)\end{array}$ \\
\hline Med Educ $z t$ & $\begin{array}{l}-0.021^{* *} \\
(0.0067)\end{array}$ & $\begin{array}{l}0.017^{* *} \\
(0.0041)\end{array}$ & $\begin{array}{l}0.010^{* *} \\
(0.0013)\end{array}$ & $\begin{array}{l}0.015^{* *} \\
(0.0023)\end{array}$ & $\begin{array}{l}-0.030^{* *} \\
(0.0039)\end{array}$ \\
\hline High Educ $_{z t}$ & $\begin{array}{l}-0.011^{* *} \\
(0.0031)\end{array}$ & $\begin{array}{l}-0.033^{* *} \\
(0.0035)\end{array}$ & $\begin{array}{l}-0.004^{* *} \\
(0.0009)\end{array}$ & $\begin{array}{l}-0.020^{* *} \\
(0.0017)\end{array}$ & $\begin{array}{l}0.015^{* *} \\
(0.0025)\end{array}$ \\
\hline Arable Land $_{z t}$ & $\begin{array}{l}0.004^{* *} \\
(0.0005)\end{array}$ & $\begin{array}{l}0.0002 \\
(0.0005)\end{array}$ & $\begin{array}{c}-0.0003^{*} \\
(0.0002)\end{array}$ & $\begin{array}{l}0.003^{* *} \\
(0.0003)\end{array}$ & $\begin{array}{l}0.003^{* *} \\
(0.0004)\end{array}$ \\
\hline $\begin{array}{l}\text { Industry } \\
\text { Specification }\end{array}$ & $\begin{array}{l}\text { Food } \\
\text { (SP4) }\end{array}$ & $\begin{array}{l}\text { Textile } \\
\text { (SP4) }\end{array}$ & $\begin{array}{l}\text { Paper } \\
(\text { SP4) }\end{array}$ & $\begin{array}{l}\text { Other } \\
\text { (SP4) }\end{array}$ & $\begin{array}{l}\text { Constr } \\
\text { (SP4) }\end{array}$ \\
\hline Cty-year dummies & yes & yes & yes & yes & yes \\
\hline F-statistic & 29.74 & 3716.51 & 20.22 & 46.14 & 18.20 \\
\hline Prob $>F$ & 0.0000 & 0.0000 & 0.0000 & 0.0000 & 0.0000 \\
\hline R-squared & 0.57 & 0.43 & 0.63 & 0.53 & 0.68 \\
\hline $\begin{array}{l}\text { Sum of Coeff. } \\
\text { Linear Homog } \\
\text { (p-value) } \\
\text { Maddala-Wu } \\
\text { (p-value) }\end{array}$ & $\begin{array}{l}-0.0052 \\
(0.0004) \\
\text { Reject } \\
(0.1650) \\
\text { Accept }\end{array}$ & $\begin{array}{l}0.0084 \\
(0.0000) \\
\text { Reject } \\
(0.0005) \\
\text { Reject }\end{array}$ & $\begin{array}{l}0.0027 \\
(0.0000) \\
\text { Reject } \\
(0.0322) \\
\text { Reject }\end{array}$ & $\begin{array}{l}0.0060 \\
(0.0000) \\
\text { Reject } \\
(0.0192) \\
\text { Reject }\end{array}$ & $\begin{array}{l}-0.0074 \\
(0.0000) \\
\text { Reject } \\
(0.0238) \\
\text { Reject }\end{array}$ \\
\hline
\end{tabular}

Notes: Huber-White heteroscedasticity robust standard errors in parentheses. ${ }^{* *}$ denotes significance at the $5 \%$ level,

* denotes significance at the $10 \%$ level. 


\section{References}

Amiti, M (1999) 'Specialization Patterns in Europe', Weltwirtschaftliches Archiv, 135(4), 573-593.

Barro, R and Sala-i-Martin, X (1995) Economic Growth, McGraw-Hill.

Bernstein, J and Weinstein, D (1998) 'Do Endowments Predict the Location of Production? Evidence from National and International Data', NBER Working Paper, 6815.

Bowen, H, Leamer, E, and Sveikauskas, L (1987) 'Multicountry, Multifactor Tests of the Factor Abundance Theory', American Economic Review, 77, 791-809.

Brulhart, M (2000) 'Evolving Geographical Specialization of European Manufacturing Industries', mimeograph, University of Lausanne.

Brulhart, M and Torstensson, J (1996) 'Regional Integration, Scale Economies and Industry Location in the European Union', CEPR Discussion Paper, 1435.

Cameron, G and Muellbauer, J (1998) 'The Housing Market and Regional Commuting and Migration Costs', Scottish Journal of Political Economy, 45(4), 420-46.

Davis, D, Weinstein, D, Bradford, S, and Shimpo, K (1997) 'Using International and Japanese Regional Data to Determine When the Factor Abundance Theory of Trade Works', American Economic Review, 87(3), 421-46

Davis, D and Weinstein, D (1996) 'Does Economic Geography Matter for International Specialization?', NBER Working Paper, 5706.

Davis, D and Weinstein, D (1998) 'An Account of Global Factor Trade', NBER Working Paper, 6785, November.

Davis, D and Weinstein, D (1999) 'Economic Geography and Regional Production Structure: An Empirical Investigation', European Economic Review, 43, 379-407.

Dixit, A and Norman, V (1980) The Theory of International Trade, Cambridge: Cambridge University Press.

Fujita, M, Krugman, P, and Venables, A (1999) The Spatial Economy: Cities, Regions, and International Trade, MIT Press.

Gabaix, X (1997) 'The Factor Content of Trade: A Rejection of the Heckscher-Ohlin-Leontief Hypothesis', Harvard University, mimeo.

Gandal, N, Hanson, G, and Slaughter, M (1999) 'Rybczynski Effects and Adjustment to Immigration in Israel', Paper presented at CEPR ERWIT conference, mimeograph.

Griliches, Z and Hausman, J (1986) 'Errors in Variables in Panel Data', Journal of Econometrics, $31,93-118$.

Hanson, H and Slaughter, M (1999) 'The Rybczynski Theorem, Factor-Price Equalization, and Immigration: Evidence from US States', NBER Working Paper, 7074.

Harrigan, J (1995) 'Factor Endowments and the International Location of Production: Econometric Evidence for the OECD, 1970-85', Journal of International Economics, 39, 123-41. 
Harrigan, J (1997) 'Technology, Factor Supplies, and International Specialization: Estimating the Neoclassical Model', American Economic Review, 87(4), 475-94.

Harrigan, J and Zakrajsek, E (1999) 'Factor Supplies and Specialization in the World Economy', paper presented at Tilburg conference on Growth, Dynamics and International Trade, mimeo.

Helpman, E (1981) 'International Trade in the Presence of Product Differentiation, Economies of Scale, and Monopolistic Competition: A Chamberlin-Heckscher-Ohlin Approach', Journal of International Economics, 11(3), 305-40.

Helpman, E and Krugman, P (1985) Market Structure and Foreign Trade, MIT Press.

Im, K, Pesaran, M, and Shin, Y (1997) 'Testing for Unit Roots in Heterogeneous Panels', University of Cambridge, mimeo.

Kohli, U (1991) Technology, Duality and Foreign Trade, Ann Arbor: University of Michigan Press.

Krugman, P (1981) 'Intra-industry Specialization and the Gains from Trade', Journal of Political Economy, 89(5), 959-74.

Krugman, P (1991) Geography and Trade, MIT Press.

Leamer, E (1980) 'The Leontief Paradox Reconsidered', Journal of Political Economy, 88(3), 495-503.

Leamer, E (1984) Sources of Comparative Advantage: Theories and Evidence, MIT Press.

Leontief, W (1953) 'Domestic Production and Foreign Trade: The American Capital Position Reexamined', Proceedings of the American Philosophical Society, 97, 332-49.

Levin, A and Lin, C (1992) 'Unit Root Tests in Panel Data: Asymptotic and Finite-sample Properties', University of California, San Diego, Discussion Paper, 92-23.

Machin, S and Van Reenen, J (1998) 'Technology and Changes in Skill Structure: Evidence from Seven OECD Countries', Quarterly Journal of Economics, November, 1215-44.

Maddala, G and Wu, S (1999) 'A Comparative Study of Unit Root Tests with Panel Data and a New Simple Test', Oxford Bulletin of Economics and Statistics, Special Issue, 631-52.

McCormick, B (1997) 'Regional Unemployment and Labour Mobility in the United Kingdom', European Economic Review, 41(3-5), 581-89.

Midelfart-Knarvik, K, Overman, H, and Venables, A (2000) 'Comparative Advantage and Economic Geography: Estimating The Location of Production in the EU', CEPR Discussion Paper, 2618.

Nickell, S and Bell, B (1996) 'Changes in the Distribution of Wages and Unemployment in OECD Countries', American Economic Review, 86(2), 302-8.

Nickell, S, Redding, S, and Swaffield, J (2000) 'Educational Attainment and Specialization in OECD Countries', Paper presented at CEPR ERWIT Conference, London School of Economics, mimeograph.

Pedroni, P (1999) 'Critical Values for Cointegration Tests in Heterogeneous Panels with Multiple Regressors', Oxford Bulletin of Economics and Statistics, Special Issue, 653-70.

Pesaran, M, Shin, Y, and Smith, R (1998) 'Pooled Mean Group Estimation of Dynamic Heterogeneous Panels', University of Cambridge, mimeo. 
Proudman, J and Redding, S (1998) 'Persistence and Mobility in International Trade', Chapter 2 in (eds) Proudman, J and Redding, S, Openness and Growth, Bank of England.

Proudman, J and Redding, S (2000) 'Evolving Patterns of International Trade', Review of International Economics, August, 8(3), pages 373-96.

Redding, S (1999) 'The Dynamics of International Specialization', CEPR Discussion Paper, 2287.

Quah, D (1994) 'Exploiting Cross-section Variation for Unit Root Inference in Dynamic Data', Economics Letters, 44, 9-19.

Trefler, D (1995) 'The Case of the Missing Trade and Other Mysteries', American Economic Review, 85(5), pages 1029-46.

Vera-Martin, M (2000) 'Specialization in European Regions', mimeograph, London School of Economics.

Woodland, A (1982) International Trade and Resource Allocation, North Holland: Amsterdam. 


\section{CENTRE FOR ECONOMIC PERFORMANCE \\ Recent Discussion Papers}

Labour Law and Social Insurance in the New Economy: A Debate on the Supiot Report

499

A. Manning

498
A. Charlwood

497
M. Keil
D. Robertson
J. Symons

496
A. Di Liberto

J. Symons

495 S. Redding

A. J. Venables

494 A. Bryson

493

D. Metcalf

492

R. Gomez

S. M. Lipset

N. Meltz

$491 \quad$ S. Burgess
J. Lane
D. Stevens

$490 \quad$ S. Burgess

S. Profit

489

S. Nickell

G. Quintini

$488 \quad$ S. Nickell

J. Van Reenen

487 M. M. Tudela

486 D. Sturm
A Generalised Model of Monopsony

Why Do Non-Union Employees Want to Unionise?

Evidence from Britain

Minimum Wages and Employment

Education and Italian Regional Development

Economic Geography and International Inequality

Union Effects on Managerial and Employee Perceptions of Employee Relations in Britain

British Unions: Dissolution or Resurgence Revisited

Frustrated Demand for Unionisation: the Case of the

United States and Canada Revisited

Jobs, Workers and Changes in Earnings Dispersion

Externalities in the Matching of Workers and Firms in

Britain

Nominal Wage Rigidity and the Rate of Inflation

Technological Innovation and Performance in the United

Kingdom

Explaining Currency Crises: A Duration Model Approach

Product Standards, Trade Disputes and Protectionism 
Mind the Gaps: The Evolution of Regional Inequalities in V. Monastiriotis the UK 1982-1997

484 H. G. Overman Y. Ioannides

483 H. G. Overman Y. Ioannides

482 Y. Ioannides H. G. Overman

481 H. G. Overman

$480 \quad$ S. Gomulka

479 S. Nickell

T. Jones

G. Quintini

$478 \quad$ C. Dougherty

$477 \quad$ P. Willman

476 D. Marsden

S. French

K. Kubo

475 S. Gomulka

474 S. Burgess

H. Turon

473 D. Robertson

J. Symons

$472 \quad$ B. Bell

S. Nickell

G. Quintini

Macroeconomic Policies and Achievements in Transition Economies, 1989-1999

Unemployment Dynamics, Duration and Equilibrium:

Evidence from Britain

Factor Residuals in SUR Regressions: Estimating Panels Allowing for Cross Sectional Correlation

Wage Equations, Wage Curves and All That

To order a discussion paper, please contact the Publications Unit Tel 02079557673 Fax 02079557595 Email info@cep.lse.ac.uk Web site http://cep.lse.ac.uk 